\title{
Design and Test of Dual Actuator Nose Wheel Steering System for Large Civil Aircraft
}

\author{
Ming Zhang, ${ }^{1}$ Rongmin Jiang, ${ }^{1}$ and Hong Nie ${ }^{1,2}$ \\ ${ }^{1}$ Key Laboratory of Fundamental Science for National Defense-Advanced Design Technology of Flight Vehicle, \\ Nanjing University of Aeronautics \& Astronautics, Nanjing 210016, China \\ ${ }^{2}$ State Key Laboratory of Mechanics and Control of Mechanical Structures, Nanjing University of Aeronautics \& Astronautics, \\ Nanjing 210016, China
}

Correspondence should be addressed to Ming Zhang; zhm6196@nuaa.edu.cn

Received 5 March 2016; Revised 18 August 2016; Accepted 31 August 2016

Academic Editor: Kenneth M. Sobel

Copyright (C) 2016 Ming Zhang et al. This is an open access article distributed under the Creative Commons Attribution License, which permits unrestricted use, distribution, and reproduction in any medium, provided the original work is properly cited.

In order to improve aircraft ground handling characteristics and airport working efficiency, large handling angle and torque are requested for the nose wheel steering system of large civil aircraft. A following swivel selector valve is firstly designed to meet the demand for the hydraulic pressure commutating as soon as the dual actuator nose wheel steering mechanism passes through its dead center position. Considering the multiple objective functions of nose wheel steering mechanisms, those core design parameters are multiobjective optimized. A nose wheel steering electrohydraulic servo system with handling and antishimmy functions is designed for the steering mechanism. Then the prototypes of the steering mechanism and electrohydraulic servo system are researched to validate the design. Using the swing actuator to provide the load torque and ground excitation, the steering test bench is prepared to test the system working. The steering test and the antishimmy test are conducted to verify the functions of the system. The test results, such as steer angle, steer torque hydraulic pressure, and antishimmy torque, are analyzed in detail and compared with the theoretical results. The results show that the property of the prototype achieves the design objectives, such as work mode, steer angle, and steer torque.

\section{Introduction}

Nose wheel steering system is the key part for the aircraft to taxi, maneuver, take off, and land. It plays a very important role in improving brake life, correcting course in tire blasting accidents, and reducing aircraft take-off and landing accidents, as shown in [1-5]. The modern civil aircraft use it to roll out and turn off quickly to reduce the runway occupancy time. Large civil aircraft puts the requirements for large handling angle and large handling torque to steering system. Gear-rack and dual actuator nose wheel steering mechanisms are the widely used style in large civil aircraft steering system. A320 and A340 adopt gearrack steer mechanism. A330, A380, and almost all Boeing civil aircrafts B737/747/767/777/787 use dual nose wheel mechanisms, because theoretically the dual actuator nose wheel steering mechanism can provide much larger steer torque under the same hydraulic pressure and occupancy volume.
It is shown by Chen et al. [6] that the steer control technology develops increasingly, from mechanical operation system and mechanical-hydraulic operation system to electrical control and hydraulic operation system. The Boeing's aircrafts, B737/747/767/777, widely use mechanical-hydraulic nose wheel steering system, and the Airbus's aircrafts, A320/330/340/380, widely use electrohydraulic steering system. Electrohydraulic steering system has the advantages of light weight and convenient maintenance and detection, so Boeing's aircraft B787 begins to use electrohydraulic nose wheel steering system. It is the trend of the development and it will be equipped in most large civil aircraft.

In order to research the dual nose wheel mechanisms, a key problem of how to change the direction of supply pressure while one actuator moves across the dead point must be solved. The second problem is to make the electrohydraulic system have both the steering and antishimmy functions. There is no very related references about this found in the papers. Most of the papers about steering system concentrate 


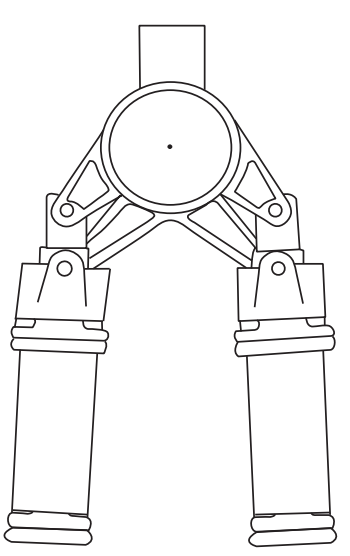

Mid-position

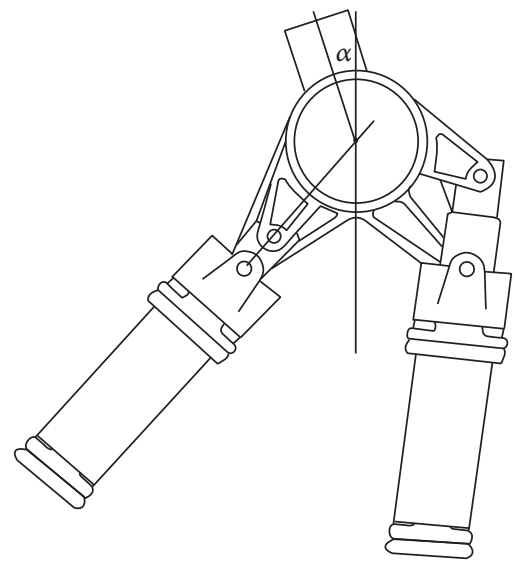

Dead center position (left)

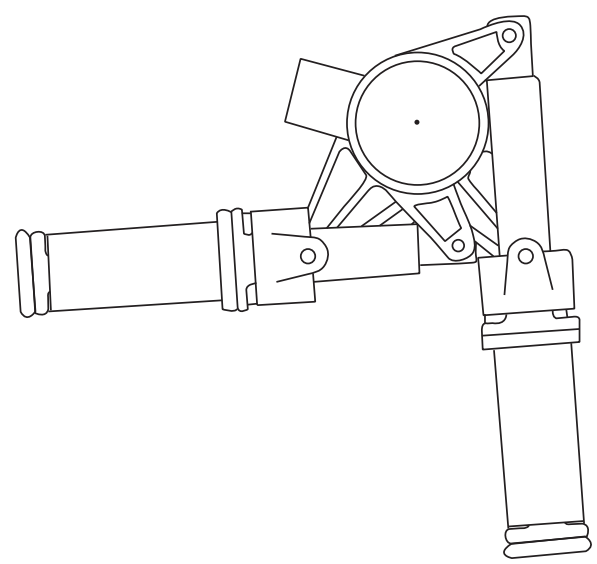

Limiting position (left)

FIGURE 1: Three node states definition of the moving process.

on system simulation and ground handling simulation. The numerical simulation is carried out by Zhang et al. [7] for the aircraft dynamic response while landing and taxiing on dry ground with antiskid braking. Zhang and Nie [8] introduce a cosimulation method to study the ground maneuvers of aircraft antiskid braking and steering. The fuzzy control method of airplane nose wheel steering turning based on improved immune genetic algorithm is researched in [9]. Zhou et al. [10] research the reconfiguration simulation of aircraft landing gear nose wheel control system. In [11], the digital fly-by-wire nose wheel steering system is proposed based on the mechanic-hydraulic one. The digital dualredundant controller of NWSS is put forward based on DSP module TMS320F2812. In SAE papers [12, 13], the design requirements of nose wheel steering system are described.

This paper takes the dual actuator nose wheel steering system for the research object. A swivel selector valve and an electrohydraulic servo system are designed for the dual actuator nose wheel steering mechanism. For the verification of the system's steering and antishimmy function, its test physical prototype is researched and the test bench is established. Test results indicate that the nose wheel steering system can meet the design requirements of work mode, steer angle, steer torque, and so forth.

\section{Design of the Dual Actuator Nose Wheel Steering Mechanism}

As shown in Figure 1, three node states are extracted from the moving process of the dual actuator nose wheel steering mechanism: mid-position, dead center position (left or right), and limiting position (left or right). From mid-position to the left dead center position, the piston rod of the left actuator retracts and the piston rod of the right actuator extends to steer the nose wheel left. From the left dead center position to the left limiting position, the left and right actuator extend jointly to steer the nose wheel left, as shown in [14]. So steering system must be designed to solve the problem of the hydraulic fluid direction reversal while the steer actuator moves at the left or right dead point.

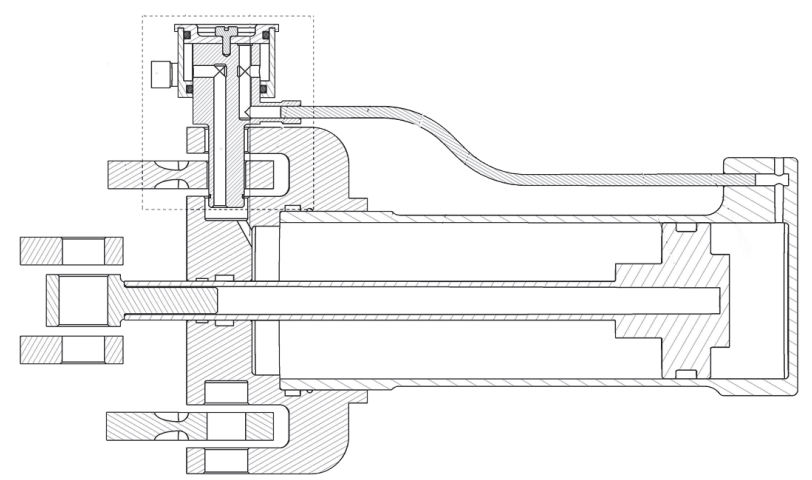

FIgURE 2: Assembly parts profile of the swivel reversal valve and actuator.

A following swivel reversal valve is designed, shown in Figures 2 and 3. This valve sends the hydraulic pressure to the necessary end of the actuator. The valve has two primary components, a post and a sleeve. The post turns in the sleeve as the steering actuator turns to follow the nose wheels. The post is attached to the actuator collar and goes through to supply an attachment point for the actuator. There are two holes through the post. One hole goes to the annulus side of the piston; the other goes to the external pipe. The sleeve has two holes. Each hole aligns with one of the holes in the post. A pin goes from the sleeve to the attachment bracket to hold the sleeve stable. When a hydraulic pressure goes into the sleeve, it goes (through one of the holes in the post) to the correct end of the actuator. The pressure of each end of the actuator can reverse at the predetermined steer angle without external drive and control feedback.

In order to obtain the maximum steer torque and steer angle at the condition of the minimum volume and mass, multiobjective optimization is conducted for the dual actuator nose wheel steering mechanism. According to the simplified model of nose steering mechanism, shown in Figure $4, h, \eta, k, \varphi$, and $\lambda$ are selected as the design variables. $(h, \eta)$ is the coordinate of $\mathrm{H}$ point and $(k, \varphi)$ is the coordinate 


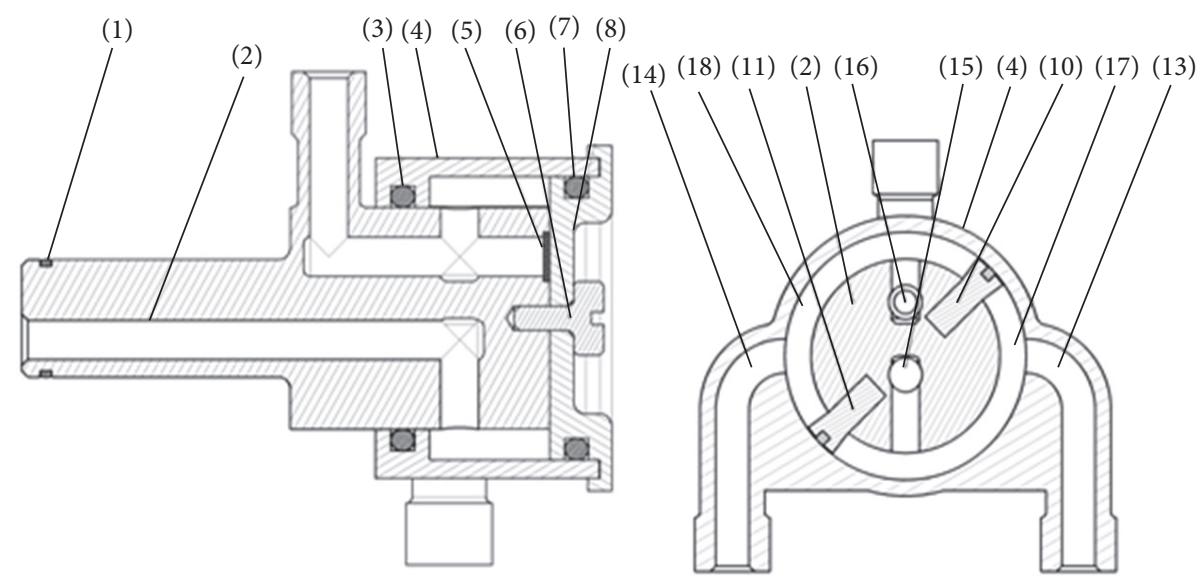

Figure 3: Profile of the following swivel reversal valve. (1) The first seal ring, (2) swivel valve core, (3) the second seal ring, (4) pressure hull, (5) gasket, (6) blot, (7) the third seal ring, (8) cover, (10) the first partial chamber bond, (11) the second partial chamber bond, (13) the first supply/return hydraulic hole, (14) the second supply/return hydraulic hole, (15) the first hole, (16) the second hole, (17) the first ring chamber, and (18) the second ring chamber.

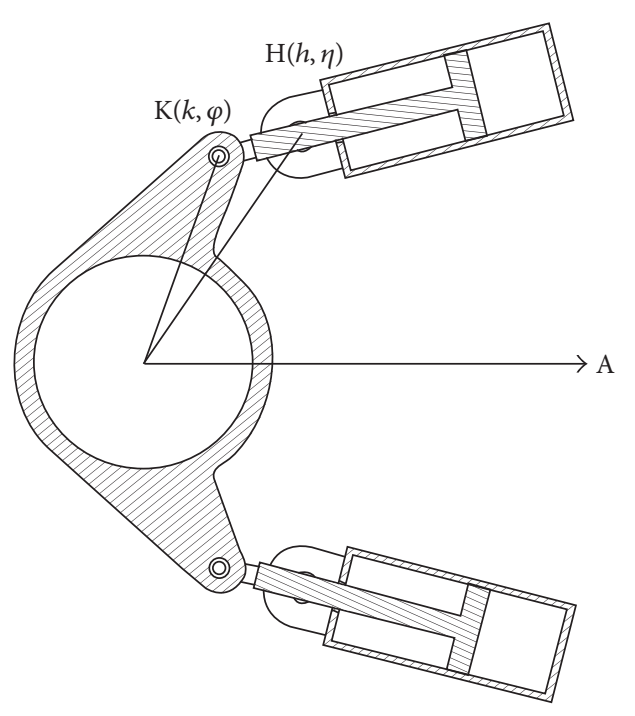

FIgURE 4: Simplified model coordinate.

of $\mathrm{K}$ point. $\lambda=D / d$ is the ratio of the actuator cylinder diameter $D$ to the actuator piston diameter $d$.

From the left limitation position $\left(\beta=-80^{\circ}\right)$ to right limitation position $\left(\beta=80^{\circ}\right)$, the motion course can be divided into four phases and the output torque can be derived in each phase.

If $\beta \in\left(-80^{\circ},-\alpha\right)$,

$$
\begin{aligned}
M_{1 l} & =\frac{\left[\left(\lambda^{2}-1\right) p-\left(\lambda^{2}+1\right) p_{0}\right] \pi d^{2}}{4} \\
\cdot & \frac{h \times k \times \sin \left[-\beta+\left(k^{\prime}-h^{\prime}\right)\right]}{\sqrt{h^{2}+k^{2}-2 h \times k \times \cos \left[-\beta+\left(k^{\prime}-h^{\prime}\right)\right]}},
\end{aligned}
$$

$$
\begin{aligned}
M_{1 r} & =\frac{\left[\left(\lambda^{2}-1\right) p-\left(\lambda^{2}+1\right) p_{0}\right] \pi d^{2}}{4} \\
\cdot & \frac{h \times k \times \sin \left[-\beta-\left(k^{\prime}-h^{\prime}\right)\right]}{\sqrt{h^{2}+k^{2}-2 h \times k \times \cos \left[-\beta-\left(k^{\prime}-h^{\prime}\right)\right]}} .
\end{aligned}
$$

If $\beta \in\left(-\alpha, 0^{\circ}\right)$,

$$
\begin{aligned}
M_{2 r} & =\frac{\left[\left(\lambda^{2}-1\right) p-\left(\lambda^{2}+1\right) p_{0}\right] \pi d^{2}}{4} \\
\cdot & \frac{h \times k \times \sin \left(k^{\prime}-h^{\prime}-\beta\right)}{\sqrt{h^{2}+k^{2}-2 h \times k \times \cos \left(k^{\prime}-h^{\prime}-\beta\right)}}, \\
M_{2 l} & =\frac{\left[\lambda^{2} p-\left(\lambda^{2}-1\right) p_{0}\right] \pi d^{2}}{4} \\
\cdot & \frac{h \times k \times \sin \left(k^{\prime}-h^{\prime}+\beta\right)}{\sqrt{h^{2}+k^{2}-2 h \times k \times \cos \left(k^{\prime}-h^{\prime}+\beta\right)}} .
\end{aligned}
$$

If $\beta \in\left(0^{\circ}, \alpha\right)$,

$$
\begin{aligned}
M_{3 l} & =\frac{\left[\left(\lambda^{2}-1\right) p-\left(\lambda^{2}+1\right) p_{0}\right] \pi d^{2}}{4} \\
\cdot & \frac{h \times k \times \sin \left(k^{\prime}-h^{\prime}-\beta\right)}{\sqrt{h^{2}+k^{2}-2 h \times k \times \cos \left(k^{\prime}-h^{\prime}-\beta\right)}}, \\
M_{3 r} & =\frac{\left[\lambda^{2} p-\left(\lambda^{2}-1\right) p_{0}\right] \pi d^{2}}{4} \\
\cdot & \frac{h \times k \times \sin \left(k^{\prime}-h^{\prime}+\beta\right)}{\sqrt{h^{2}+k^{2}-2 h \times k \times \cos \left(k^{\prime}-h^{\prime}+\beta\right)}} .
\end{aligned}
$$




$$
\begin{aligned}
& \text { If } \beta \in\left(\alpha, 80^{\circ}\right), \\
& \begin{aligned}
M_{4 l} & =\frac{\left[\lambda^{2} p-\left(\lambda^{2}-1\right) p_{0}\right] \pi d^{2}}{4} \\
& \cdot \frac{h \times k \times \sin \left[\beta-\left(k^{\prime}-h^{\prime}\right)\right]}{\sqrt{h^{2}+k^{2}-2 h \times k \times \cos \left[\beta-\left(k^{\prime}-h^{\prime}\right)\right]}}, \\
M_{4 r} & =\frac{\left[\lambda^{2} p-\left(\lambda^{2}-1\right) p_{0}\right] \pi d^{2}}{4} \\
& \cdot \frac{h \times k \times \sin \left[\beta+\left(k^{\prime}-h^{\prime}\right)\right]}{\sqrt{h^{2}+k^{2}-2 h \times k \times \cos \left[\beta+\left(k^{\prime}-h^{\prime}\right)\right]}},
\end{aligned}
\end{aligned}
$$

$$
\begin{aligned}
f_{1}= & (2 h \cdot \sin \eta) \cdot\left[h \cdot \cos \eta-k \cdot \cos \left(\varphi+80^{\circ}\right)\right] \\
f_{2}= & \frac{\pi}{4}\left[\sqrt{h^{2}+k^{2}-2 \times h \times k \times \cos (\gamma-\eta+\varphi)}-(h-k)\right] \\
& \quad\left(10 \sqrt{\frac{4 \times M_{0} \times \lambda^{2}}{\pi\left(h \times k \times \sin [2(\varphi-\eta)] / \sqrt{h^{2}+k^{2}-2 h \times k \times \cos [2(\varphi-\eta)]}\right)\left[\left(p-p_{0}\right) \lambda^{2}-p\right]}}+25\right) .
\end{aligned}
$$

where $\alpha$ is the dead point angle, $p$ is the aircraft hydraulic system supply pressure (considering the pressure loss, the aircraft system pressure is $21 \mathrm{MPa}$ ), and $p_{0}$ is the aircraft hydraulic system return pressure. $M_{i l}$ and $M_{i r}(i=1,2,3,4)$ are the output torque provided by left or right actuator in each phrase. So the total torque provided in each phrase is

$$
M_{i}=M_{i l}+M_{i r} \quad(i=1,2,3,4) .
$$

There are four objective functions: strut frame projection area $f_{1}$, steer actuator approximate volume $f_{2}$, mechanism efficiency $f_{3}$, and mechanism drive smooth degree $f_{4}$. To meet the design requirement of large steer angle and large steer torque, as well as the lightest weight, the objective functions $f_{1}$ and $f_{2}$ are
$M_{0}$ is the rated steer torque and $\gamma$ is the designed limit steer angle.

According to the relationship curve of steer torque to steer angle, the function of output torque and rated torque $f_{3}$ and output torque and steer angle $f_{4}$ are selected as objective functions:

$$
\begin{aligned}
& f_{3}=\frac{M_{0} \cdot 2 \gamma}{\int_{-\gamma}^{\gamma} M(\beta) d \beta} \times 100 \%, \\
& f_{4}=1-\frac{M(\beta)_{\max }-M(\beta)_{\min }}{\bar{M}(\beta)} \times 100 \% .
\end{aligned}
$$

$M(\beta)$ is the steer torque at different angle, $\beta$ is the steer angle, $M(\beta)_{\max }$ is the maximum steer torque, $M(\beta)_{\min }$ is the minimum steer torque, and $\bar{M}(\beta)$ is the average steer torque.

According to the triangle of $\mathrm{H}, \mathrm{K}$, and axle center or the triangle of $\mathrm{H}^{\prime}, \mathrm{K}^{\prime}$, and axle center, the constraint condition is derived via sine theorem and cosine theorem.

In $[15,16]$, our research team designs the steering mechanism with the steer angle $80^{\circ}$ and the steer torque $12000 \mathrm{Nm}$. In this paper, before producing the steering mechanism, the design objective of steer torque is changed to $7000 \mathrm{Nm}$, because of new requirement of the large civil aircraft. Based on the software of iSIGHT8.0, the multiobjective optimization model is established with Nondominated Sorting Genetic Algorithm-II (NSGA2). The optimal design results are shown in Table 1.

Using the optimal design parameter, the digital prototype of the dual actuator nose wheel steering mechanism is shown in Figure 5. The relationship of the steer torque versus steer angle is shown in Figure 6. Under the condition of 16.55 MPa hydraulic press and $0.55 \mathrm{MPa}$ return press, the steering mechanism can provide $7366-14933 \mathrm{Nm}$ steer torque while the steer angle changes in the range of $-80^{\circ} \sim 80^{\circ}$ (+ represents the motion from the mid-position to the dead position; - represents the motion from the dead position to the mid-position). The minimum steer torque $7366 \mathrm{Nm}$ occurs at the dead position $-20^{\circ}$, and the maximum steer torque $14933 \mathrm{Nm}$ occurs at the steer angle $50^{\circ}$. So if the constant torque $7000 \mathrm{Nm}$ is requested, the provided pressure by the hydraulic system varies with angle, as shown in Figure 7. The maximum pressure request is $15.79 \mathrm{MPa}$.

\section{Design of Electrohydraulic Servo System}

The handling system for the actuator is an electrohydraulic servo system, which has steering and shimmy damping function. Steering inputs are from the hand wheel or the rudder pedals. Figures 8 and 9 show the two control modes by the hand wheel and the rudder pedals separately. When the pilot turns the hand wheel to maximum, the nose wheels turn a maximum of 80 degrees in the left or right direction. When the pilot turns the rudder pedal to maximum, the nose wheels turn a maximum of 8 degrees in the left or right direction. The hand wheel is used in the low speed. When the ground speed of the aircraft is more than 10 knots the angle of steering available decreases. This decrease continues in proportion to the speed. The rudder pedals are used in high speed during take-off or landing. The maximum steering 


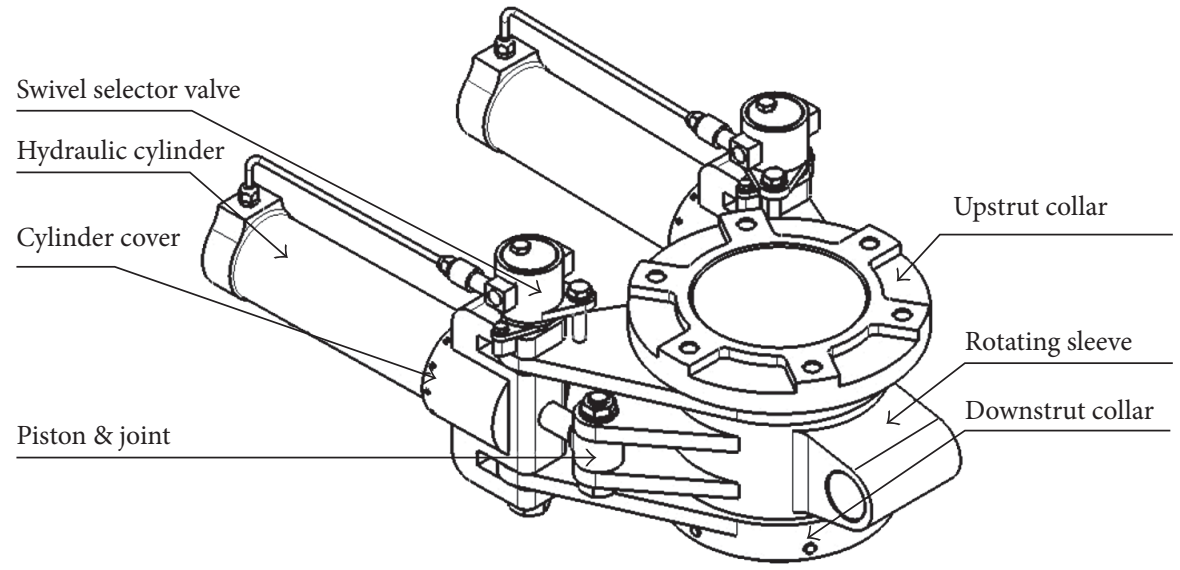

FIGURE 5: Design model of dual actuator nose wheel steering mechanism.

TABLE 1: Optimal design results.

\begin{tabular}{lc}
\hline Parameter name & Value \\
\hline$M / \mathrm{Nm}$ & 7000 \\
$\gamma /{ }^{\circ}$ & 80 \\
$\alpha /^{\circ}$ & 20 \\
$p / \mathrm{MPa}$ & 16.55 \\
$p_{0} / \mathrm{MPa}$ & 0.55 \\
$d_{c} / \mathrm{mm}$ & 88 \\
$D / \mathrm{mm}$ & 64 \\
$d / \mathrm{mm}$ & 16 \\
$h / \mathrm{mm}$ & 200 \\
$k / \mathrm{mm}$ & 153 \\
$\eta / \mathrm{deg}$ & 44 \\
$\varphi / \mathrm{deg}$ & 64 \\
$\lambda$ & 4 \\
$f_{1} / \mathrm{mm}^{2}$ & 64390 \\
$f_{2} / \mathrm{mm}^{3}$ & 114720 \\
$f_{3}$ & $45.23 \%$ \\
$f_{4}$ & $33.76 \%$ \\
\hline
\end{tabular}

$d_{c}$ is nose gear strut cylinder diameter.

angle decreases after the speed of the aircraft becomes more than 50 knots. When the speed is more than 150 knots, the steering function cannot work and nose wheel is free while the shimmy damping is working.

According to the motion characteristics and requirements of the dual actuator nose wheel steering mechanism, the fly-by-wire handling servo system is selected for it. Besides, it should have steering and antishimmy working modes. The system has two operation modes, namely, hand wheel operation and rudder pedal operation. The hand wheel operation is mainly used for the large angle steering movement as the aircraft is taxiing with low speed; however, the rudder pedal operation is mainly used for adjusting the direction of the aircraft speed in the landing stage.

The pilot selects the working mode through the state conversion module in the control panel. When the system is

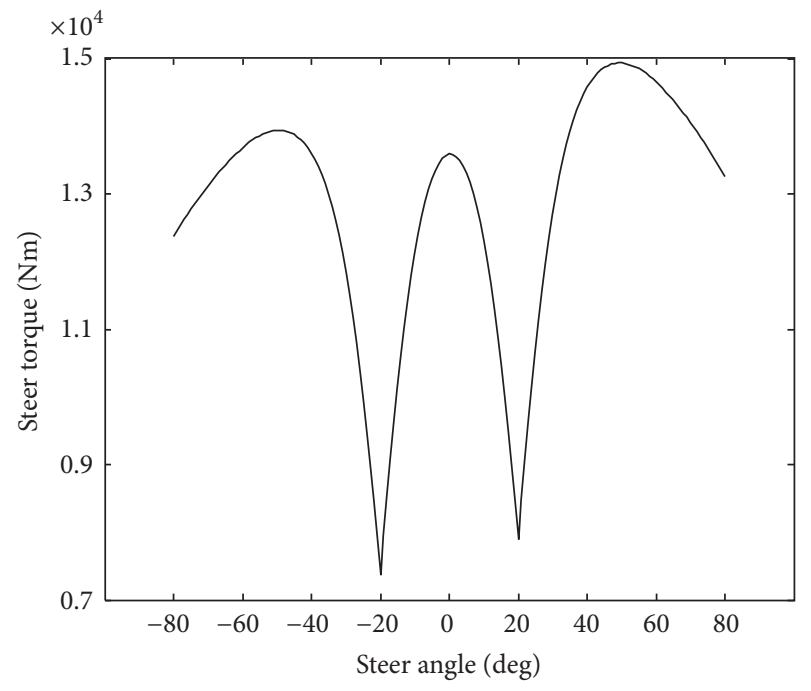

FIgURE 6: Steer torque versus steer angle at constant pressure $16.55 \mathrm{MPa}$.

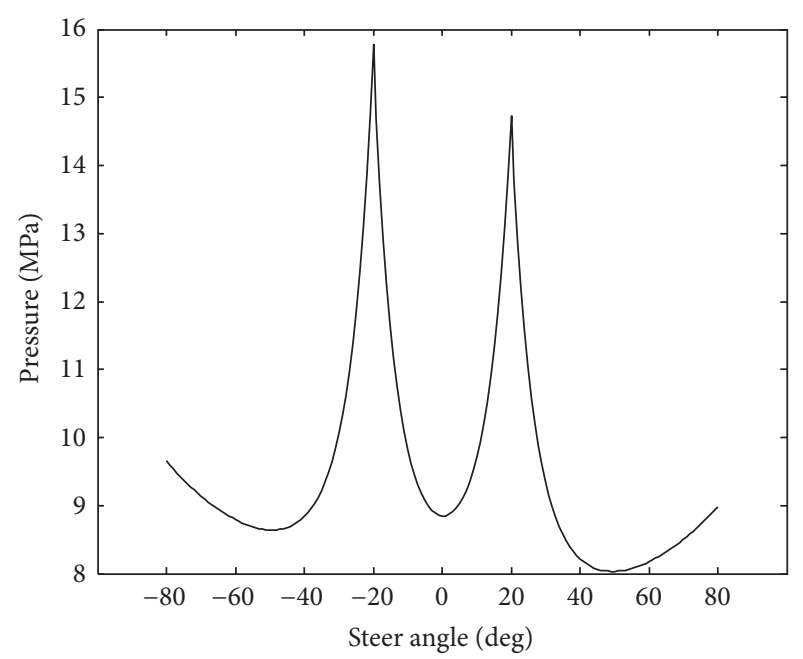

FIGURE 7: Request pressure at the constant torque $7000 \mathrm{Nm}$. 


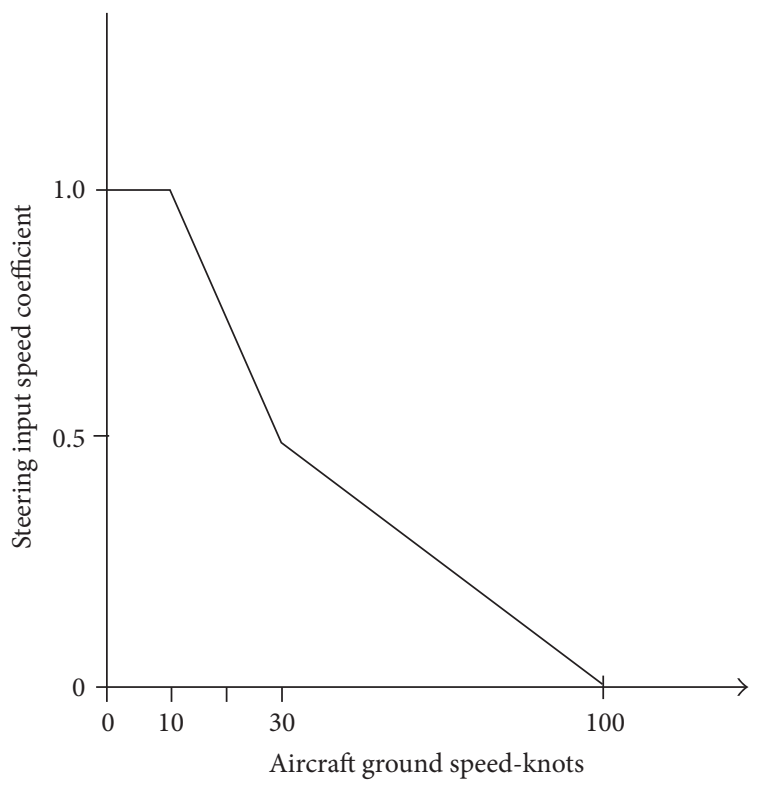

FIGURE 8: Hand wheel operation model.

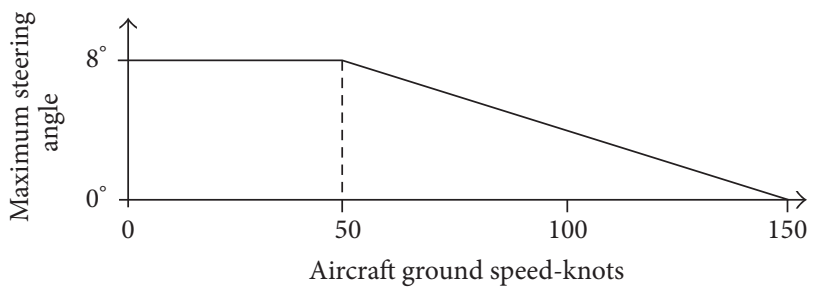

FIGURE 9: Rudder pedal operation model.

in steering mode, the steering input from the hand wheel or rudder pedal is transmitted to the controller. The steering system has electrical control and hydraulic operation. Electrical components supply steering inputs to electrohydraulic valves in a hydraulic system. The electrohydraulic valves control the flow of hydraulic fluid to hydraulic actuators that move the steering mechanism. Feedback sensors in the system supply the correct position signals for the steering mechanism. The basic control principle is shown in Figure 10.

An electrohydraulic servo control system which is made up of four main function modules is designed on the basis of the above design requirement. The four modules are the mode selector module, pressure maintaining module, safe and antishimmy module, and swivel commutating module, which consist of a micron filter, a check valve, a selector valve, a bypass valve, a servo valve, an accumulator, a pressure maintaining valve, two antishimmy interchangeable valves, two return valves, two safety valves, two swivel selector valves, steering angle feedback, and two actuators, as shown in Figure 11.

The selector valve is an electrically operated ball type valve. An electromagnetic coil moves a plunger which pushes a ball against a seat to control the flow of hydraulic fluid. The electrical connector and hydraulic ports are plug-in type. The bypass valve is installed between the servo valve and the

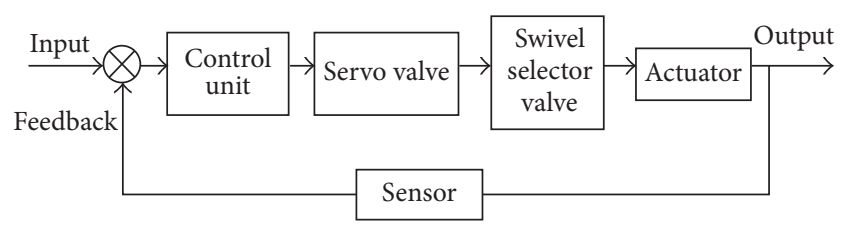

FIGURE 10: Basic control principle of the steering system.

antishimmy valves. A hydraulic pressure operates the valve to isolate the service lines from each other and to connect the service lines together and to the return line. The servo valve is an electrohydraulic valve that supplies a hydraulic pressure in proportion to an electrical input. The antishimmy valves are installed in the two service lines. The valves can operate together or independently to control the flow of hydraulic fluid through each line. These valves have three functions: to permit a free flow out of the service line, to decrease the return flow through the service line to a specified limit, and to permit an increase in the return flow through the service line if the pressure is more than a specified limit. The accumulator holds a quantity of pressurized hydraulic fluid to prevent cavitation. The pressure maintaining valve is installed between the accumulator and the outlet port. Its function is to hold a specified pressure in the hydraulic block. The return valves open to let fluid into the low-pressure actuator service line. When the pressure in the circuit (from the maintaining valve and the accumulator) is more than in the service line, the valve opens to prevent cavitation. These prevent fluid cavitation in the low-pressure service line of the actuator during nose wheel shimmy.

When the selector valve opens, a control pressure also goes through to the bypass valve. This operates to isolate the steering actuator service lines from each other. When the hand wheels, the rudder pedals, or the autopilot makes a steering input the data goes to the SCU (Steer Control Unit). The SCU calculates the servo valve control current (the difference between the necessary angle and the correct nose wheel position). It does this to get the necessary steering direction and the speed of the turn. The SCU energizes the servo valve to connect the hydraulic pressure to the correct service line. At the same time, the servo valve sensor sends the data (that gives the position of the spool) to the monitor channel of the SCU.

The supply pressure goes to the necessary end of each steering actuator through the hydraulic block and the rotating selector valves.

It does this to get the steering direction as follows:

(i) From 0 to 20 degrees, the full bore end of one steering actuator and the annulus of the other

(ii) From 20 degrees to the maximum steering angle, the full bore end of the two steering actuators

If a force causes unwanted angular movement of the nose wheels (when the aircraft moves at high speed and the wheel is free) the related antishimmy valve operates as a pressure relief valve. It does this to let more hydraulic fluid return from the steering actuators. If a greater force occurs, the 


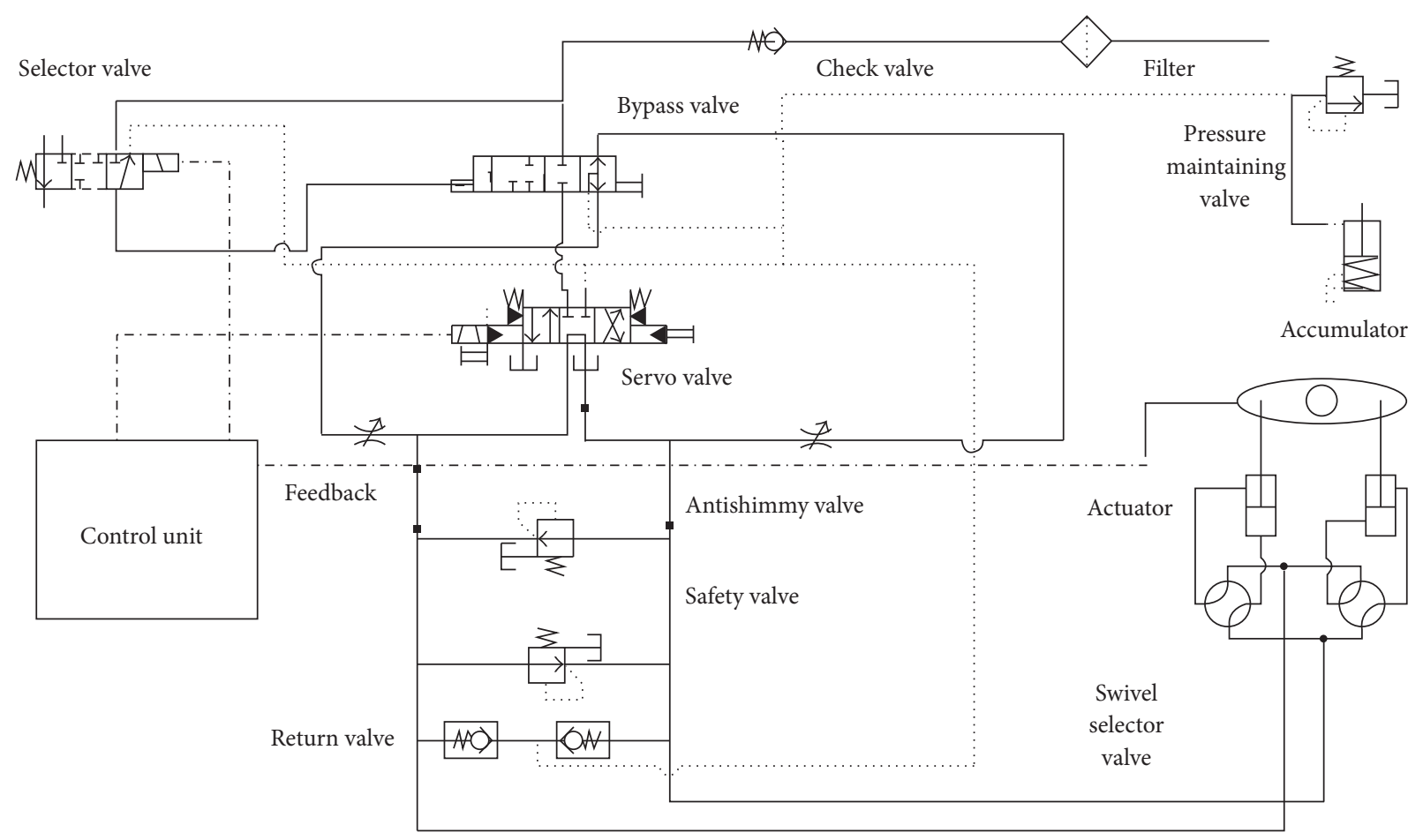

FIGURE 11: Design of the electrohydraulic system.

bypass valve also operates to connect the service lines to each other and to the return. This lets the fluid go to the other antishimmy valve and to the return line so that the pressures in the actuators become the same. If cavitation occurs in the other service line, the related refilling valve opens to increase the fluid pressure. The pressure in the accumulator and the reduced pressure in the service line cause the valve to open.

\section{The Simulation Analysis of the Nose Wheel Steering System}

Through the analysis of the basic control cycle on the electrohydraulic servo system for aircraft nose wheel steering and the function of hydraulic components, the simulation model of the dual actuator nose wheel steering system is established in LMS Imagine.lab AMESim, as shown in Figure 12. Then the model is operated to analyze and test the steering and antishimmy function of the system.

\subsection{The Simulation Analysis in the Hand Wheel Operation} Mode. Figure 13 shows the curve of the system input changing with time in hand wheel operation mode, whose zero position is defined as the piston position where the volume of the cylinder rear end is zero. The curve of system input means that the aircraft nose wheel moves from the mid-position to one side limiting position; then it maintains position for a while and returns to the mid-position.

Figure 14 shows the relationship curve of the piston displacement in two actuators changing with time. As can be seen, at first, actuator 1 (the right actuator) extends and actuator 2 (the left actuator) retracts, which make the nose wheel turn left under their combined action. When the piston in actuator 2 reaches its dead center position, it reverses automatically under the control of swivel selector valve to make the nose wheel continue turning left as the two actuators both extend. When the hand wheel reaches the maximum steering angle and stops, the piston in actuator correspondingly moves from the center position whose coordinate value is $29.8 \mathrm{~mm}$ to the maximum extension position whose coordinate value is $225.1 \mathrm{~mm}$ and stops. In the process where the hand wheel moves from the maximum turning angle to the mid-position, both of the actuators retract at the same time; meanwhile, the turning angle decreases gradually. When the piston in actuator 2 reaches the dead position again, the swivel selector valve reverses correspondingly to make actuator 1 retract and actuator 2 extend; as a result, the aircraft nose wheel turns to mid-position and then stops.

The curve of the system input and output from hand wheel changing with time is obtained in Figure 15. As can be seen, compared with system input, the output of the system has a little delay when the motion of piston starts and stops, which is acceptable in consideration of the situation of actual control. Besides, the system input is basically consistent with the output of the system, which means that the hydraulic system has a good following performance and can meet the general requirement in practical project.

4.2. The Simulation Analysis in the Rudder Pedal Operation Mode. Refer to the proposal offered in [8] about the maximum turning angle in the correcting control mode, in consideration of the proposal about the rudder pedal input in project background; the maximum turning angle of nose 


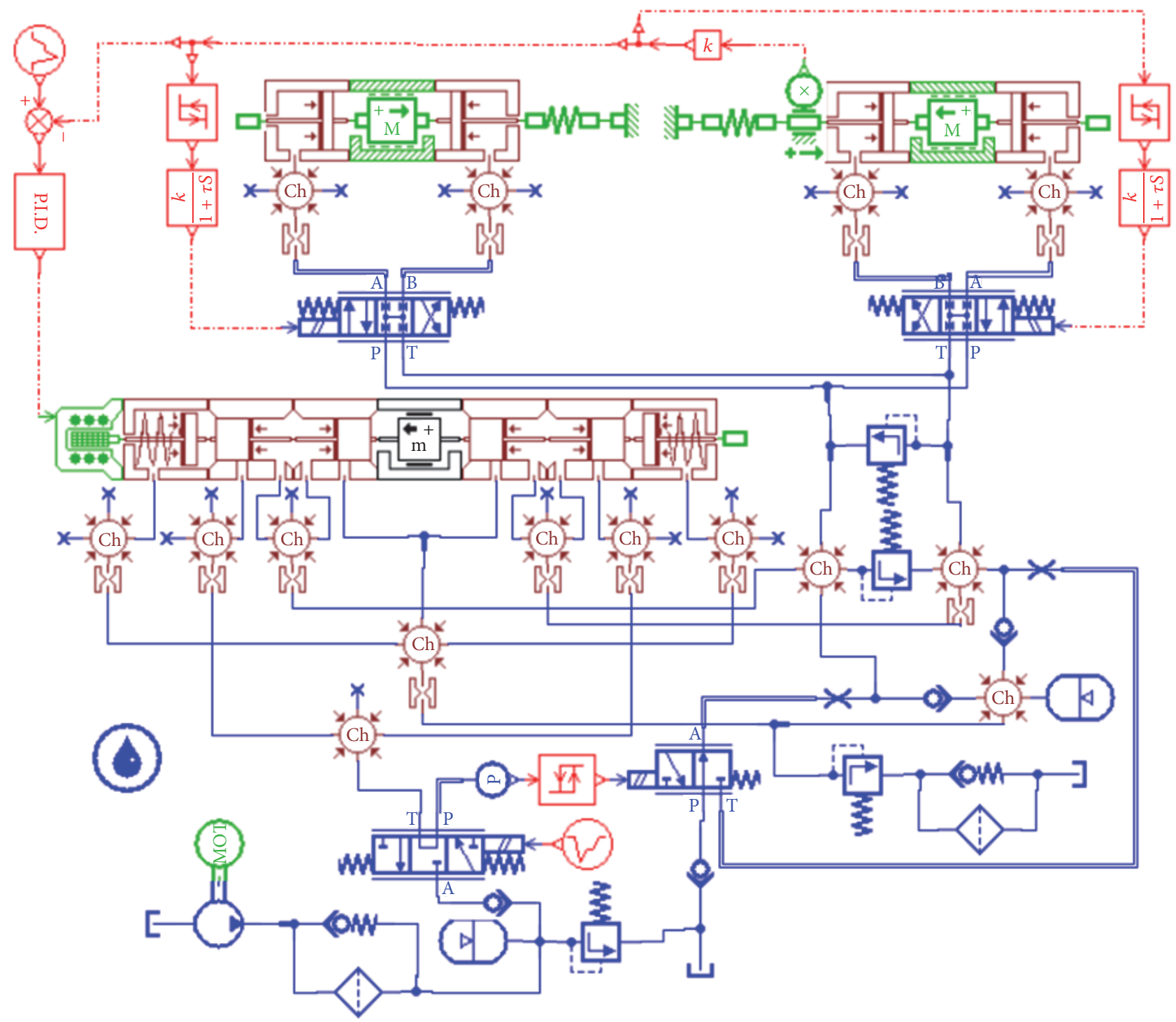

FIGURE 12: Simulation model of the dual actuator nose wheel steering system.

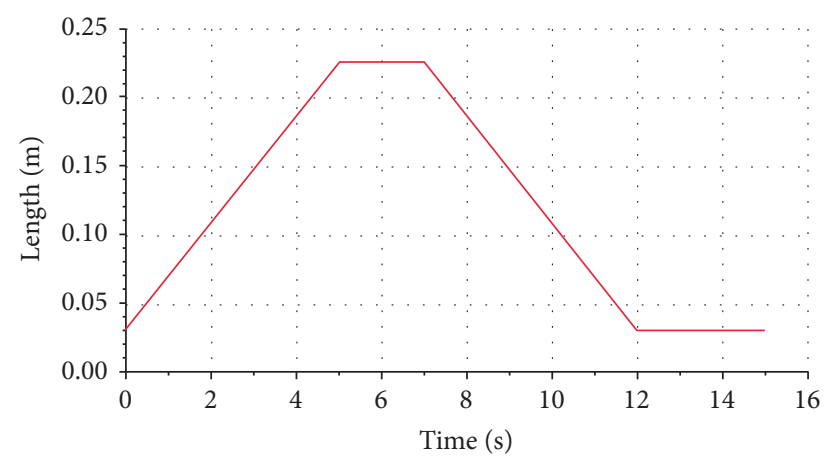

FIGURE 13: The system input versus time in hand wheel operation mode.

wheel in rudder pedal control mode is set as $8^{\circ}$; the maximum speed in the process of rudder pedal fast correction is

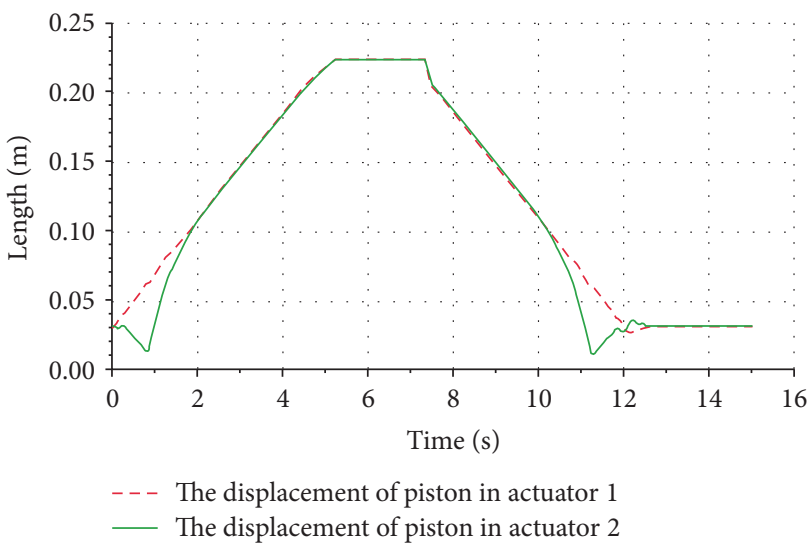

FIGURE 14: The piston displacement changing with time of each actuator. 


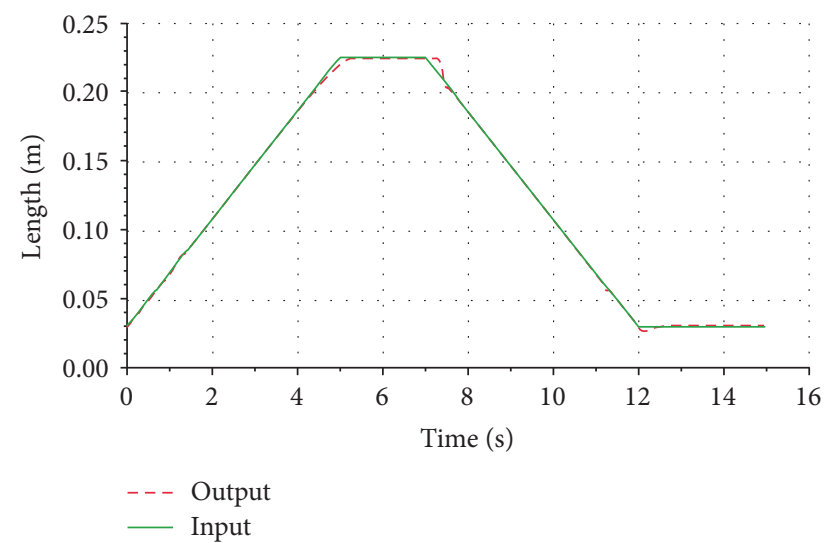

FIGURE 15: The relationship curve of the hand wheel steering system input and output changing with time.

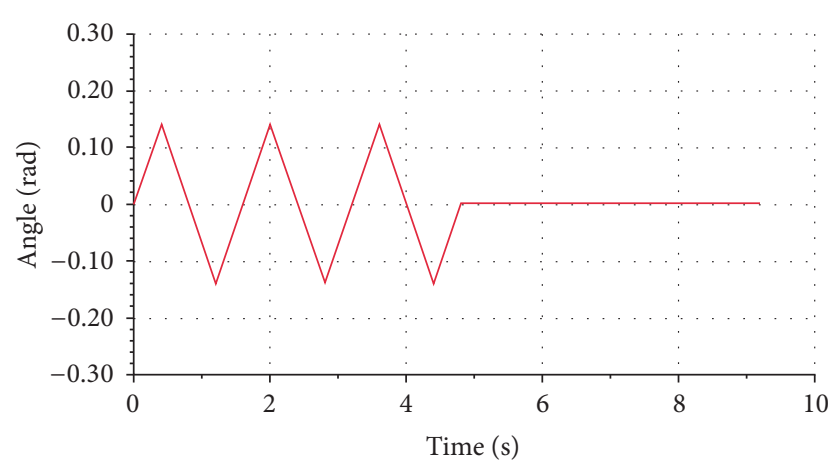

FIGURE 16: The angle input changing with time in rudder pedal operation mode.

explored in the following paragraphs. The continuous cycle whose speed is $20 \%$ is used to simulate the rudder pedal control input, as is shown in Figure 16.

Through system simulation, the relationship curve of input and output of steer angle changing with time under the steering speed being $20 \%$ is obtained in Figure 17. As can be seen from the figure, when the system input is set as a continuous uniform circle whose speed is $20^{\circ} / \mathrm{s}$, the following performance of system is bad. After 3 steering circles, the difference between input and output reaches $6.59^{\circ}$, which means that the system cannot meet general requirement in general project. This will call for using the method of adjusting the nose wheel steering speed gradually to obtain the maximum steering speed which can meet the response requirements of the steering control system.

Through a series of analysis, adjustment, and simulation, the maximum steering speed is limited to $17^{\circ} / \mathrm{s}$ to get a good following performance of the system, as can be seen in Figure 18. Thus an operating mode used in the rudder pedal operation mode when the aircraft need correction is obtained. That is using the maximum steering speed of $17^{\circ} / \mathrm{s}$ to do the fast correction control as the maximum allowable turning angle is $8^{\circ}$.

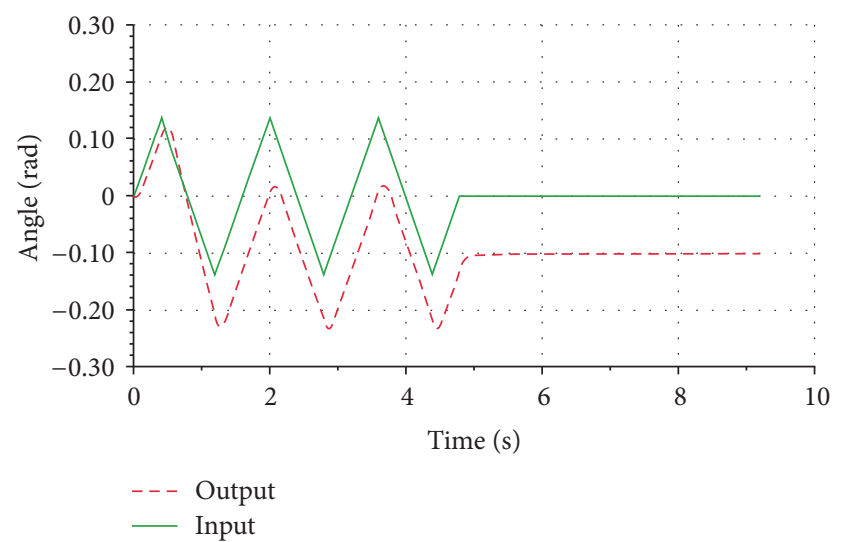

FIGURE 17: The relationship curve of input and output of steer angle changing with time under the steering speed $20^{\circ} / \mathrm{s}$.

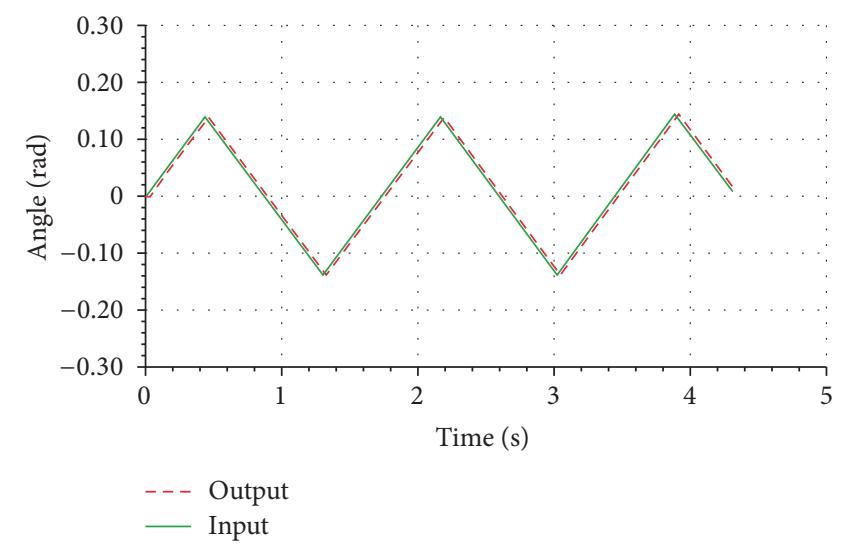

FIGURE 18: The relationship curve of input and output of steer angle changing with time under the steering speed $17^{\circ} / \mathrm{s}$.

\section{Test of Nose Wheel Steering System}

The test physical prototypes are researched according to the design results in Sections 2 and 3, including dual actuator nose wheel steering mechanism in Figure 19. The steering mechanism is installed on the landing gear strut. The hydraulic servo system includes the valves shown in Figure 20, such as a micron filter, a check valve, a selector valve, a bypass valve, a servo valve, an accumulator, a pressure maintaining valve, two antishimmy interchangeable valves, two return valves, and two safety valves.

In order to test the property of the steering mechanism and the hydraulic servo system, the ground test system is developed, as shown in Figure 21. The swivel actuator is used to provide the rotating torque to model the ground torque acted on the wheel while the system is in steering working mode. It can also provide angle excitation while the system is in antishimmy working mode. The control unit is a twochannel control system. One is used to control the steering system, and the other is used to control the load modeling system. It works on computers and controls the selector valve and servo valve to achieve the test request. 


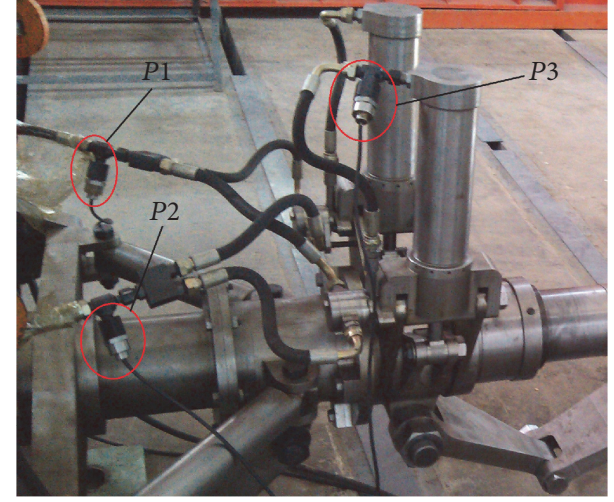

FIGURE 19: Dual actuator nose wheel steering mechanism.

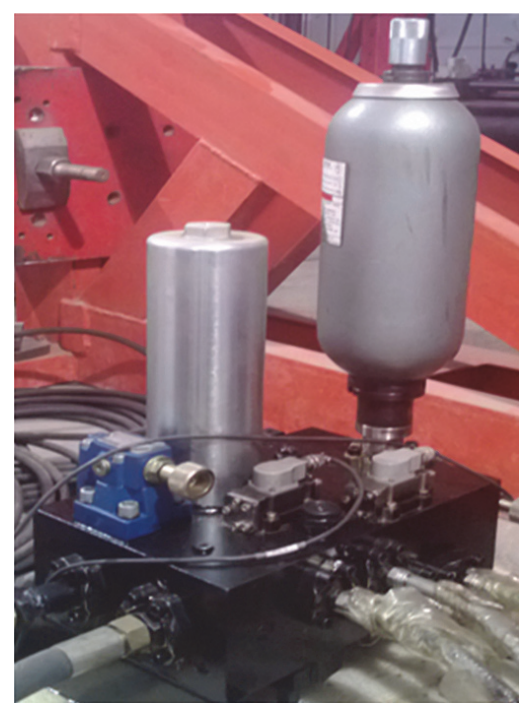

FIgURE 20: Hydraulic servo system.

The test equipment installation is shown in Figure 22, including hydraulic source, hydraulic servo system, steering actuator mechanism, swing cylinder, control system, and test system. The actuator mechanism installed on the landing gear drives the piston rotating via the torque arm. One end of the landing gear is fixed at the ground bench, and the other end is connected to the swing cylinder. The control system controls the hydraulic source and hydraulic servo system to drive the steering mechanism and swing cylinder working. The torque sensor is used to measure the load torque, the angle sensor to measure the angle, and the pressure sensor to measure the pressure.

\section{Test Results}

6.1. Steering Test. The constant load test is conducted firstly to validate the steering mechanism and the electrohydraulic servo control system. The steering system works at steering mode and the swing cylinder provides load torque at force control mode. The control order of steer angle is from $0^{\circ}$ to $80^{\circ}$, the load torque is $-7000 \mathrm{Nm}$, then the steer angle returns from $80^{\circ}$ to $0^{\circ}$, and the load torque is reversed to $7000 \mathrm{Nm}$. The responses of steer angle, load torque, and hydraulic pressure are tested to exam the functions of the system. Considering the symmetry of the two actuators, the pressure of the three holes at left actuator, $P 1, P 2$, and $P 3$, is selected to be tested, as shown in Figure 19.

6.1.1. Steering from $0^{\circ}$ to $80^{\circ}$. From $0^{\circ}$ to $20^{\circ}$, the supply pressure goes to the annulus of the left steering actuator and the full bore end of the other. The left actuator retracts and the other extends. In the range of $20^{\circ} \sim 80^{\circ}$, the supply pressure goes to the full bore end of the two steering actuators. The two actuators all extend.

Figure 23 shows the steer angles of control order and response. The max lag from the response to order is $1.76^{\circ}$. The electrohydraulic servo can follow the control order immediately. The load torque is shown in Figure 24. The response of the load torque can follow the order too. Figure 25 shows the pressure changes with the time (angle). From $0^{\circ}$ to $20^{\circ}$, the left actuator is retracting, so hydraulic pressure goes to the annulus of the actuator and its pressure is the working pressure $P 2$; the pressure of the full bore end of the left actuator $P 3$ is equal to return pressure $P 1$. From $20^{\circ}$ to $80^{\circ}$, the mechanism covers over the left dead point, and the left actuator is extending. By the rotating selector valve, hydraulic pressure goes to the full bore end of the actuator and the pressure $P 3$ jumps from return pressure to working pressure. In theory, the value of the pressure $P 2$ and pressure $P 3$ must be equal, but in test they have some differences due to the pressure flowing across holes. Comparing the request supply pressure at the same load torque, the pressure in test is somewhat larger than that in theory, as shown in Figure 26. Because, in the test, there is friction between parts of every rotating group, the system must provide larger pressure in order to overcome the same load torque.

In Figures 24 and 28, while the actuator goes across the dead point (20 degrees), the steering torque has a little oscillation, because the nonlinear hydraulic/torque gain with dead point has significant impact on maximum steering load limitation as well as on system stability and dynamic characteristics. But the system stability and dynamic characteristics cannot be analyzed well here due to the limited test conditions and application. This is a future work towards full nose wheel steering system detailed design.

6.1.2. Steering from $80^{\circ}$ to $0^{\circ}$. From $80^{\circ}$ to $20^{\circ}$, the supply pressure goes to the annulus of the two steering actuators. The two actuators all retract. From $20^{\circ}$ to $0^{\circ}$, the supply pressure goes to the full bore end of left steering actuator and the annulus of the other. The left actuator extends and the other still retracts.

Figures 27-30 show the responses of the steer angle, load torque, and pressure while steering mechanism is moving in the range of $80^{\circ} \sim 0^{\circ}$. Figure 27 shows the steer angle change from $80^{\circ}$ to $0^{\circ}$ and Figure 28 shows that the load torque keeps up with $7000 \mathrm{Nm}$. The lag between order and response is small. From $80^{\circ}$ to $20^{\circ}$, the left actuator is retracting, so hydraulic pressure goes to the annulus of the actuator and its pressure is the working pressure $P 1$; the pressure of the full 


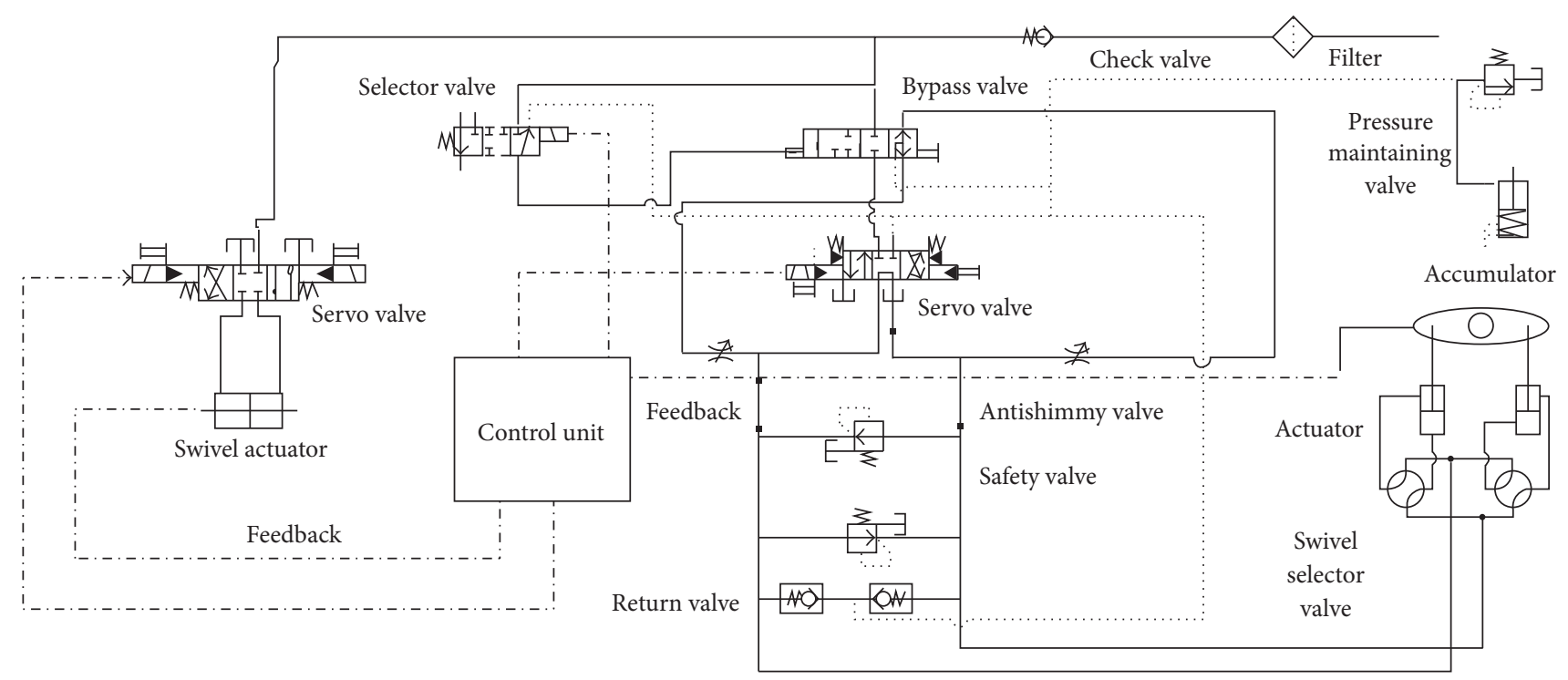

FIGURE 21: Schematic diagram of ground test system.

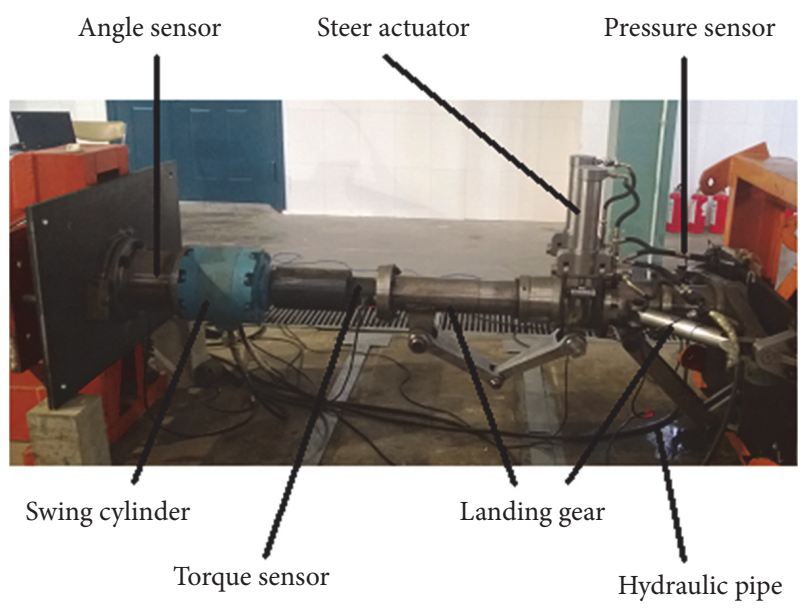

FIGURE 22: Test equipment installation.

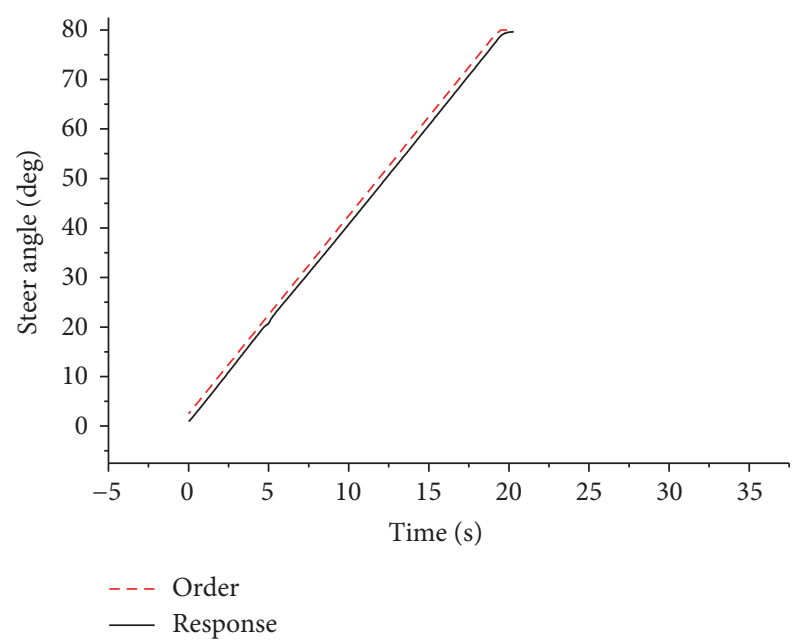

Figure 23: Steer angle.

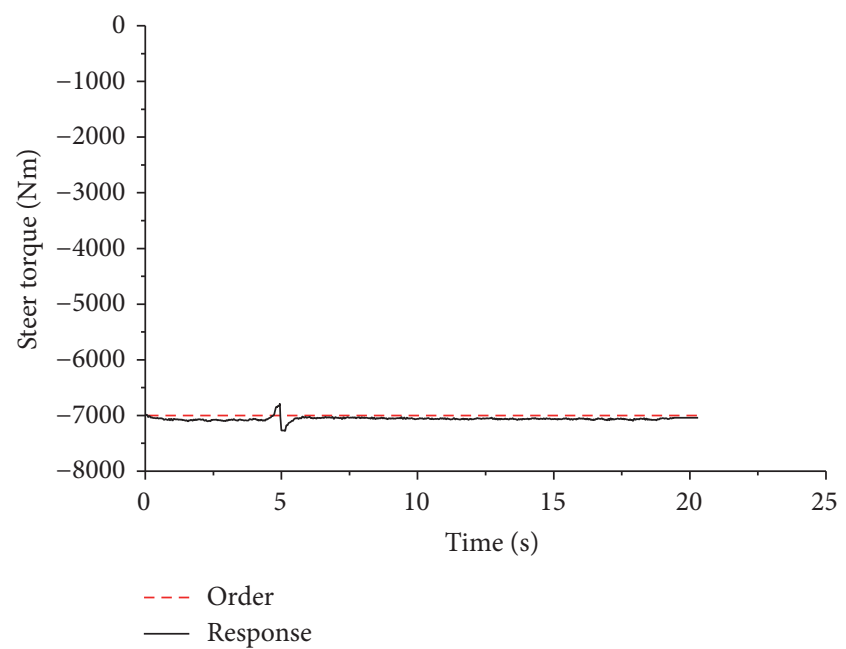

FIgURE 24: Load torque.

bore end of the left actuator $P 3$ is equal to return pressure $P 2$. From $20^{\circ}$ to $0^{\circ}$, the mechanism covers over the left dead point, and the left actuator begins to extend. By the rotating selector valve, hydraulic pressure goes to the full bore end of the actuator and the pressure $P 3$ jumps from return pressure to working pressure. In theory, the value of the pressure $P 1$ and pressure $P 3$ must be equal, but in test they also have some differences due to the pressure flowing across holes, as shown in Figure 29. The pressure in test is also somewhat larger than that in theory, as shown in Figure 30. The maximum request supply pressure is $18.7 \mathrm{MPa}$, which is smaller than the max system supply pressure $21 \mathrm{MPa}$. Therefore, the steering system can provide more than $7000 \mathrm{Nm}$ torque in the whole phrase, $0^{\circ} \sim 80^{\circ}$ and $80^{\circ} \sim 0^{\circ}$.

6.2. Antishimmy Test. In the antishimmy working mode, the selector valve is not open and the bypass valve operates 


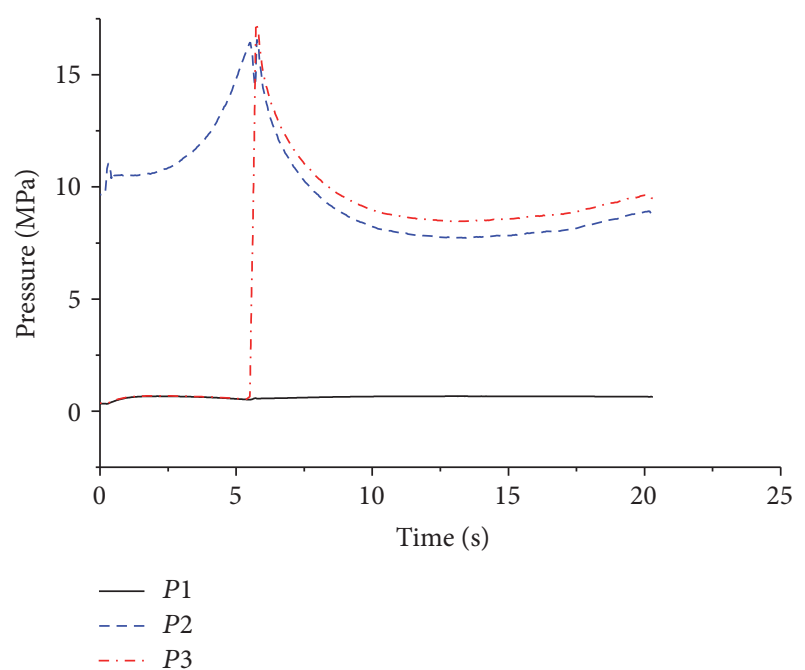

Figure 25: Pressure.

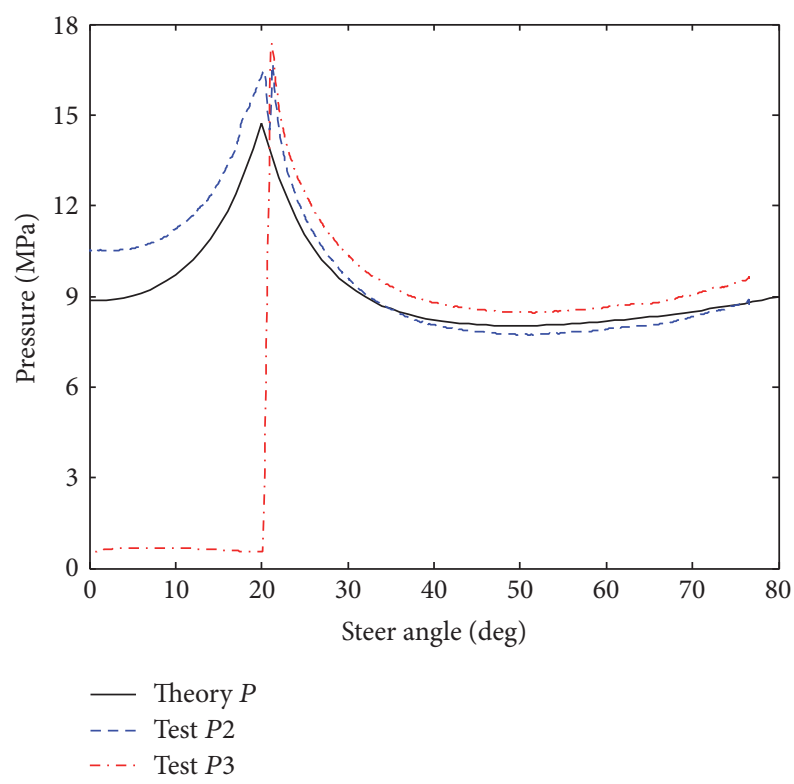

FIGURE 26: Comparison of pressure between test and theory results.

to connect the service lines of the two actuators to each other and to the return, to isolate the service line to the supply press. The related antishimmy valve operates as a pressure relief valve. The steering system is free and the swing cylinder provides excitation under the angle control mode. This models the aircraft taxiing at the excitation of nose wheel and ground interacting force.

6.2.1. Impact of Different Hole Diameters on the Antishimmy Torque. Figure 31 shows the excited angle by the swing cylinder. Figures 32-34 show the antishimmy torque produced by different hole diameters of antishimmy valves. The full open hole diameter is $4 \mathrm{~mm}$, Figure 32 is $60 \%$ full, Figure 33 is $50 \%$ full, and Figure 34 is $40 \%$ full. With the decrease of the hole diameter, the antishimmy torque is increasing. So the

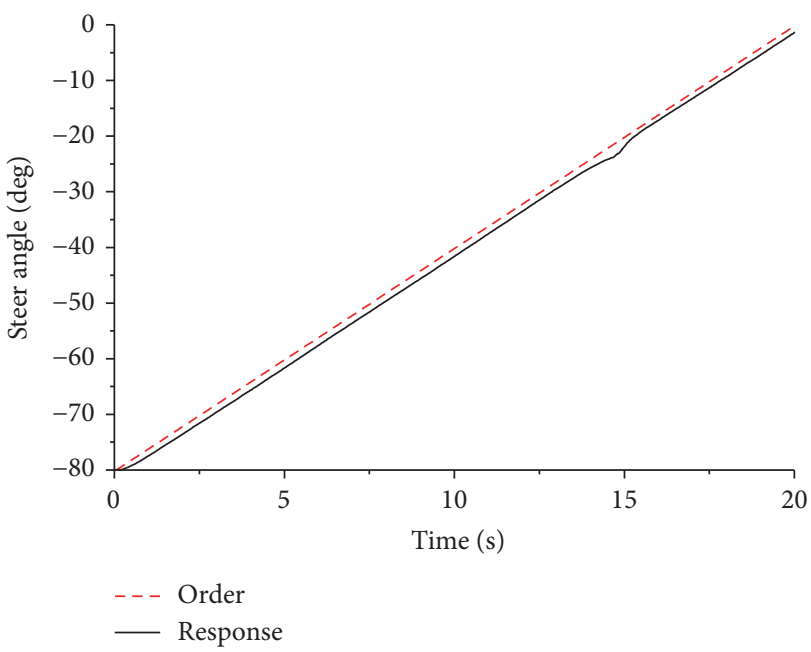

Figure 27: Steer angle.

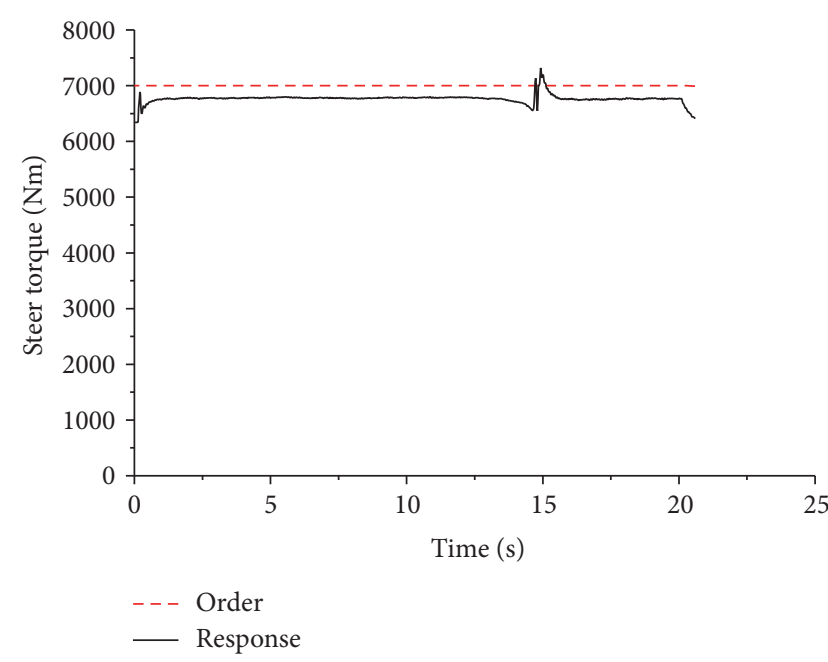

FIGURE 28: Load torque.

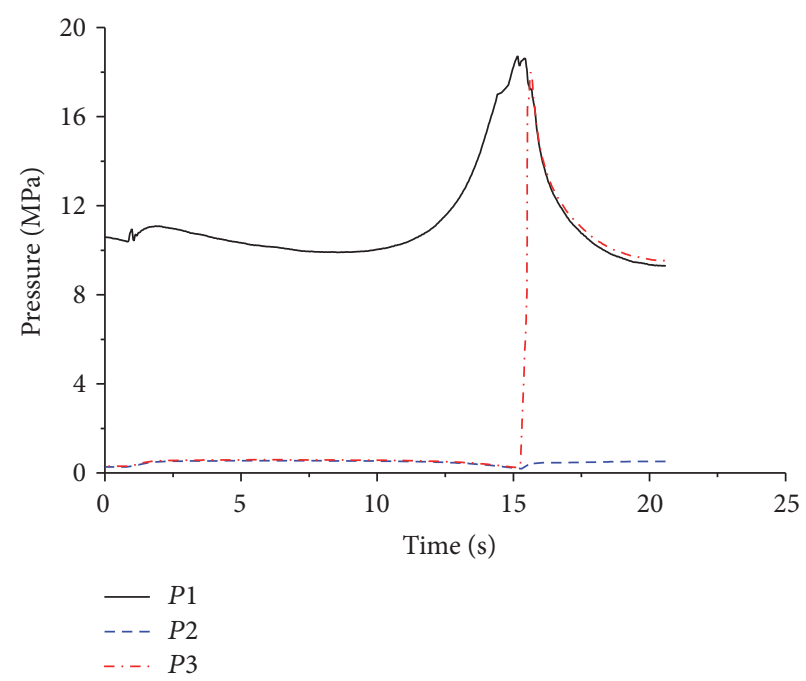

Figure 29: Pressure. 


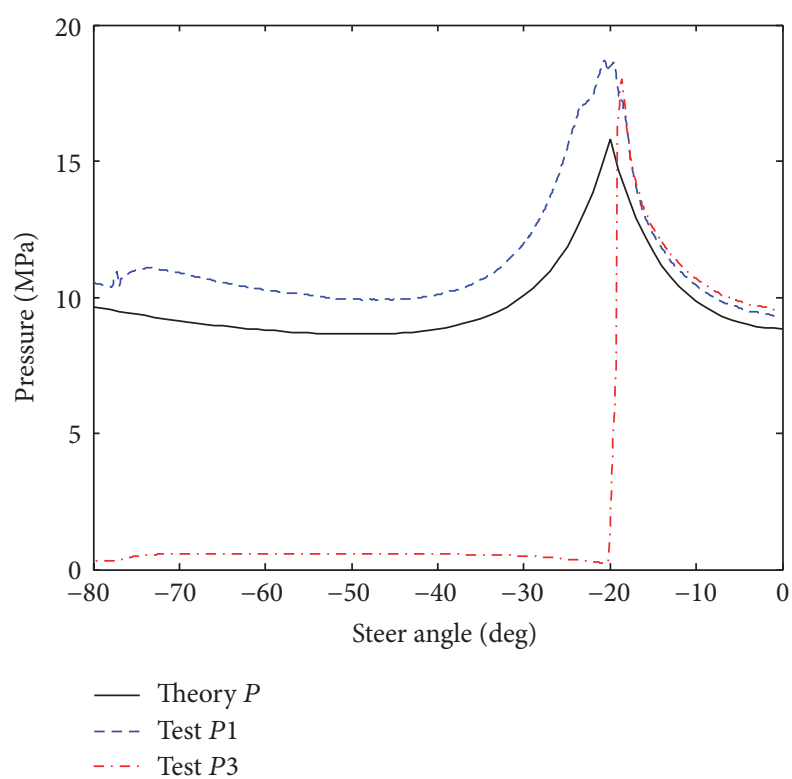

FIGURE 30: Comparison of pressure between test and theory results.

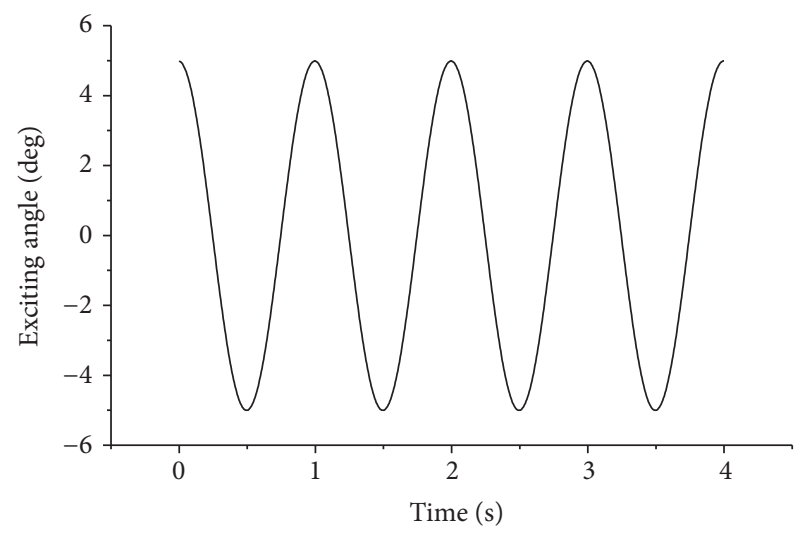

FIgURE 31: Exciting angle.

antishimmy torque can be regulated by the antishimmy valves in accordance with the requirement of preventing aircraft nose wheel from shimmying.

6.2.2. Impact of Different Shimmy Frequency on the Antishimmy Torque. Antishimmy torque affected by shimmy frequency is shown in Figure 35. With the shimmy frequency decreasing, the antishimmy torque is decreasing too. So the antishimmy valve diameter preset should consider the whole taxiing velocity to avoid too large or too small antishimmy torque.

The shimmy damping performance is not analyzed and test is adequate in this paper, for shimmy damping performance becomes even more difficult to analyze as a function of fluid/ambient temperature due to viscosity characteristics and fluid flow through antishimmy valve. Typical approach to evaluate wide spectrum of nose wheel steering shimmy characteristics is frequency response with fluid flow and pressure drop across shimmy damping device. The system

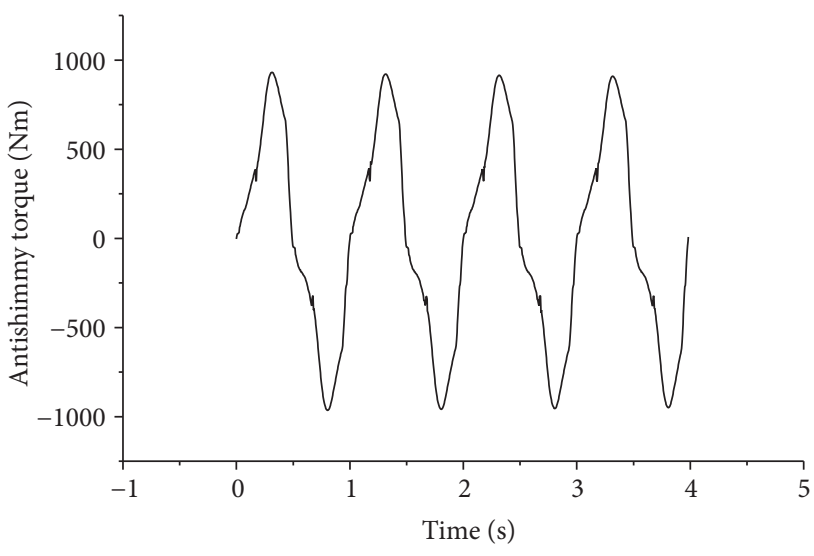

FIgURE 32: Antishimmy torque produced by antishimmy valves (1).

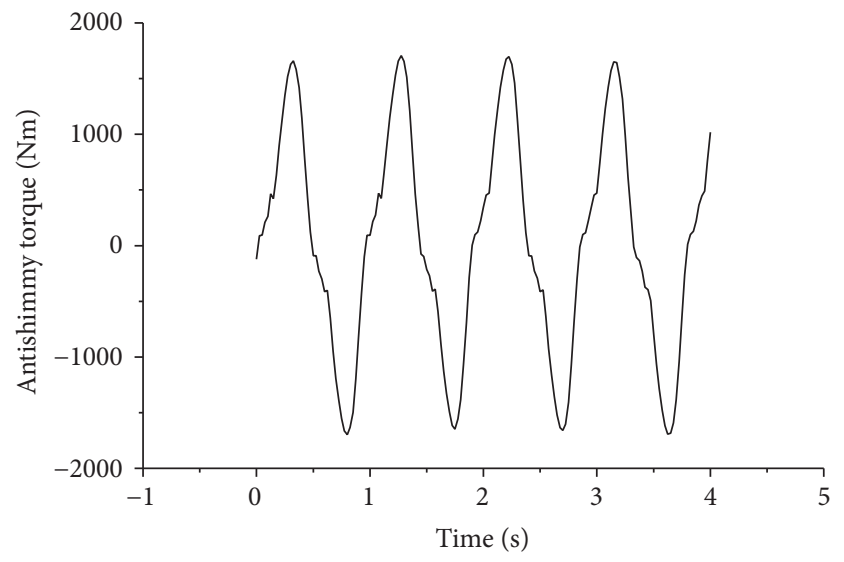

FIGURE 33: Antishimmy torque produced by antishimmy valves (2).

is proved to have the shimmy damping mode and damping adjusting function, but the performance, simulation, and tests must be studied well in future research.

\section{Conclusions}

(1) A dual actuator nose wheel steering mechanism is designed for the large civil aircraft in order to improve steer angle and steer torque. The mechanical following swivel selector valve is proposed to solve the direction change of the pressure while the actuator moves across the dead point. Under the requirement of the design torque $7000 \mathrm{Nm}$, the optimal method is used to obtain the optimal structure for the steering mechanism.

(2) An electrohydraulic servo control system is researched to move the steering mechanism. The system has two working functions of steering and antishimmy. The steering system is a position servo system, and it moves the wheel to the right angle as the control unit orders. The antishimmy valves are used to prevent the nose wheel from encountering ground turbulence while aircraft is taxiing at high velocity. 


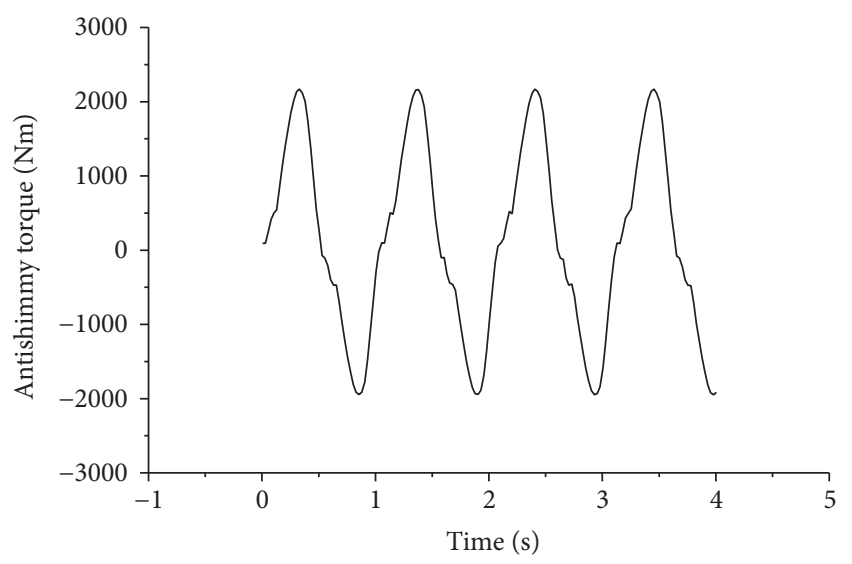

FIGURE 34: Antishimmy torque produced by antishimmy valves (3).

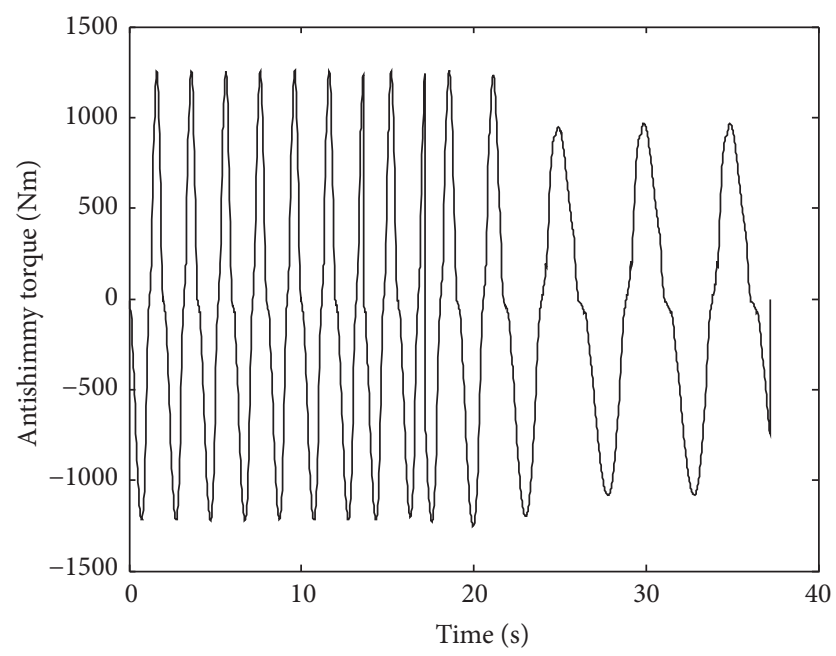

FIgURE 35: Antishimmy torque affected by shimmy frequency.

(3) The test physical prototype of the nose wheel steering system is researched and the test bench is established. Then the steering test is conducted and some parameters are tested to verify the property of the system. The results indicate that the results are much the same between theory and test and the wheel steering system can meet the design requirements, such as work mode, steer angle, and steer torque. But the system stability and dynamic characteristics cannot be analyzed well here due to the limited test conditions and application. This is a future work towards full nose wheel steering system detailed design.

(4) In the antishimmy test, impact of different hole diameters of antishimmy valves and different shimmy frequency on antishimmy torque is discussed in detail. The smaller the hole diameter is and the higher the shimmy frequency is, the larger the antishimmy torque is.

\section{Competing Interests}

The authors declare that there are no competing interests regarding the publication of this paper.

\section{Acknowledgments}

This study was supported by the Fundamental Research Funds for the Central Universities (no. NS2016001), the National Natural Science Foundation of China (no. 51305198), and the Aero-Science Fund of China (no. 20142852025).

\section{References}

[1] P. D. Khapane, "Soimulation of asymmetric landing and typical ground maneuvers for large transport aircraft," Aerospace Science and Technology, vol. 7, no. 8, pp. 611-619, 2003.

[2] P. D. Khapane, "Gear walk instability studies using flexible multibody dynamics simulation methods in SIMPACK," Aerospace Science and Technology, vol. 10, no. 1, pp. 19-25, 2006.

[3] S. H. Goldthorpe and Kernik, "Ground and control requirement for high-speed rollout and turnoff (ROTO)," Tech. Rep. NASACR-195026, NASA Langley Research Center, 1995.

[4] G. Y. Li, "Directional stability of aircraft running on runway with two transverse slopes," Journal of Traffic and Transportation Engineering, vol. 2, no. 3, pp. 112-114, 2002.

[5] L. B. Zhang and S. X. Su, "Analysis to the problem of airplane's cross-wind landing," Flight Dynamics, vol. 20, no. 4, pp. 51-55, 2002.

[6] B. Chen, Z. L. Wang, and L. H. Qiu, "Main development trend of aircraft hydraulic systems," Acta Aeronautica et Astronautica Sinica, vol. 19, no. 7, pp. s1-s6, 1998.

[7] M. Zhang, H. Nie, X. H. Wei et al., "Modeling and simulation of aircraft anti-skid braking and steering using co-simulation method," COMPEL, vol. 28, no. 6, pp. 1471-1488, 2009.

[8] M. Zhang and H. Nie, "Dynamics analysis of aircraft ground steering and braking responses," Acta Aeronautica et Astronautica Sinica, vol. 29, no. 3, pp. 616-621, 2008.

[9] Z.-H. Yuan and J. Zhang, "Fuzzy control simulation research of airplane nose wheel steering turning system," Journal of System Simulation, vol. 20, no. 17, pp. 4509-4513, 2009.

[10] X. Y. Zhou, S. P. Wang, and Z. X. Jiao, "Research of aircraft landing gear control system reconfiguration simulation," Hydraulic and Pneumatic, vol. 6, pp. 32-34, 2005.

[11] R. T. Chen, Research on digital controller design of aircraft nose wheel steering system [Dissertation], Central South University, Changsha, China, 2010.

[12] SAE Aerospace, "Aircraft nose wheel steering systems," Tech. Rep. SAE AIR 1595A-2006, 2006.

[13] SAE Aerospace, "Aircraft nose wheel steering/centering systems," Tech. Rep. SAE AIR 1752A-2006, 2006.

[14] "A330 Aircraft maintenance manual: nose wheel steering system," Tech. Rep. 32-51, 2008.

[15] B. Mi, H. Nie, and M. Zhang, "The multi-objective optimization of dual actuator nose wheel steering mechanisms on large civil aircraft," Mechanical Science and Technology for Aerospace Engineering, vol. 30, no. 8, pp. 1221-1225, 2011.

[16] Q. Nie, H. Nie, and M. Zhang, "Design and dynamic analysis of dual actuator nose wheel steering system on large civil aircraft," Journal of Nanjing University of Aeronautics \& Astronautics, vol. 40, no. 4, pp. 503-510, 2012. 


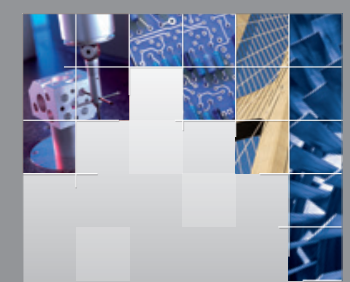

\section{Enfincering}
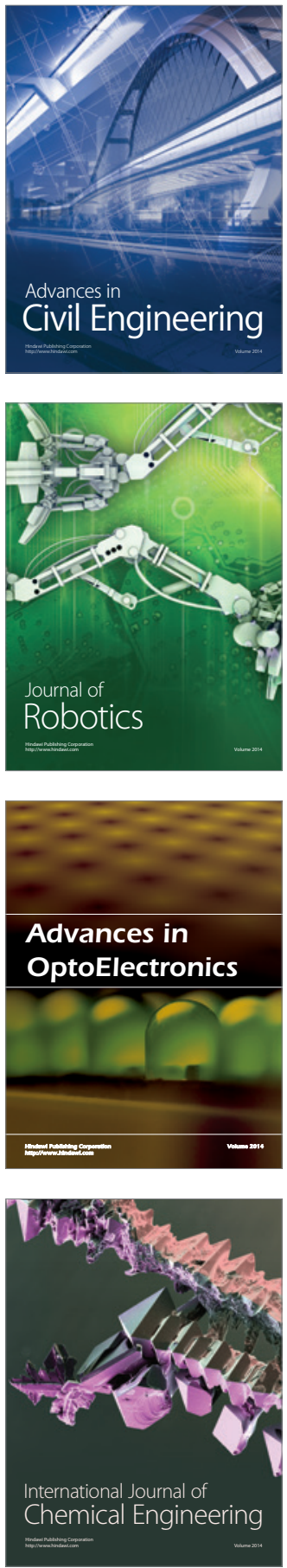

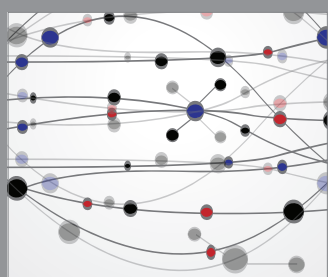

The Scientific World Journal

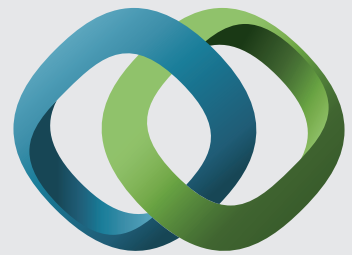

\section{Hindawi}

Submit your manuscripts at

http://www.hindawi.com
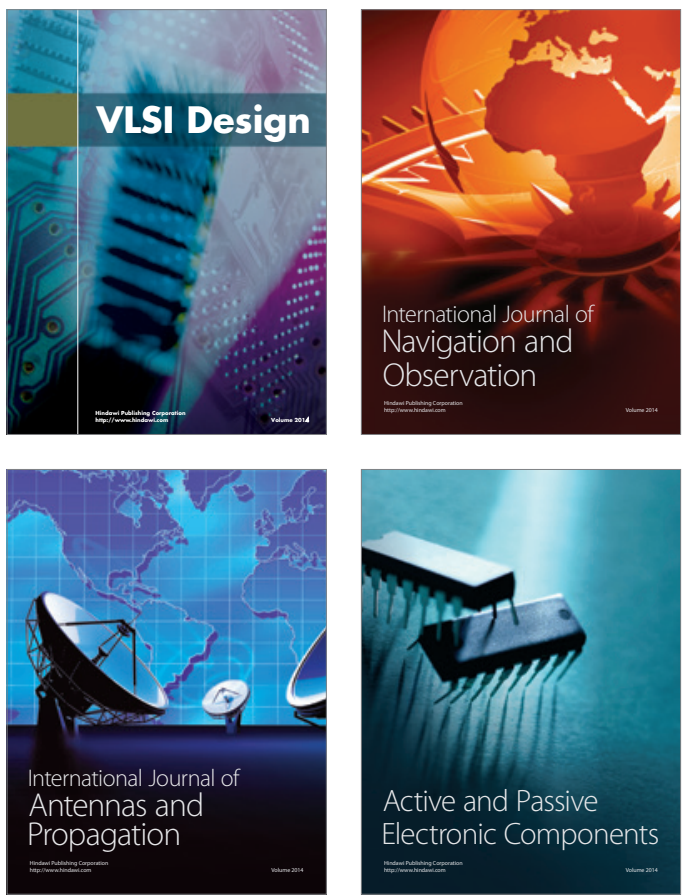
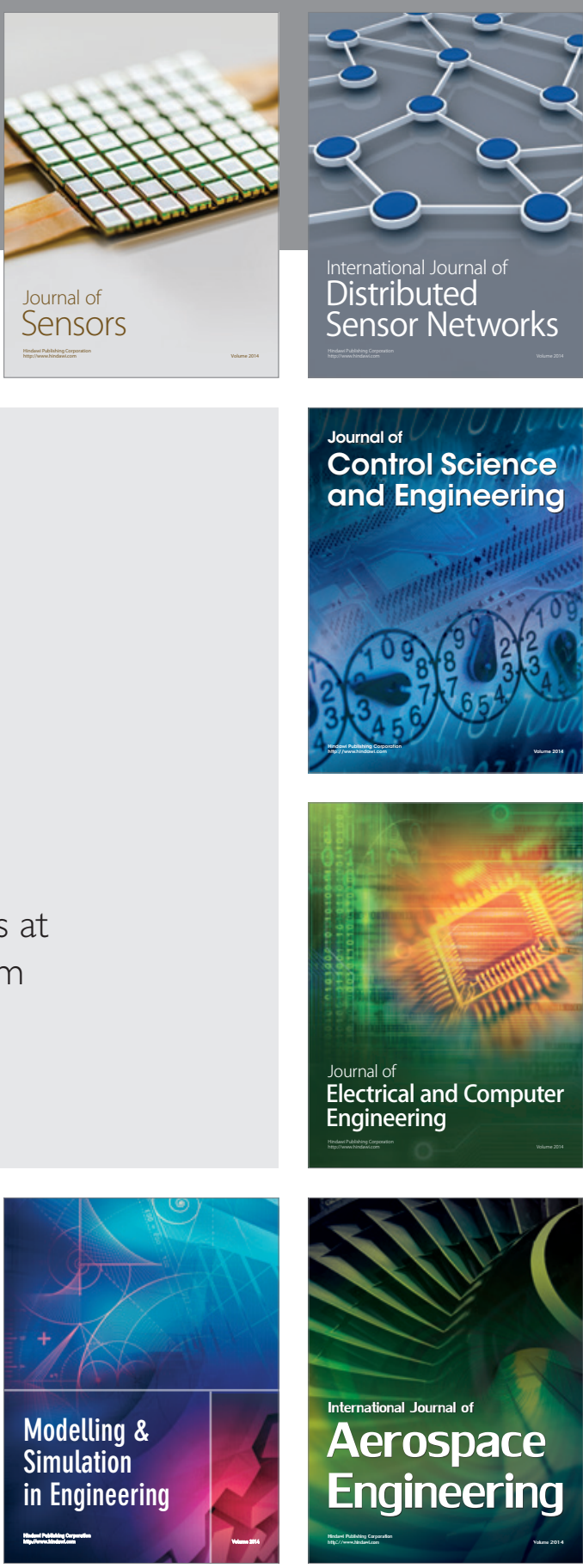

International Journal of

Distributed

Sensor Networks

Journal of

Control Science

and Engineering
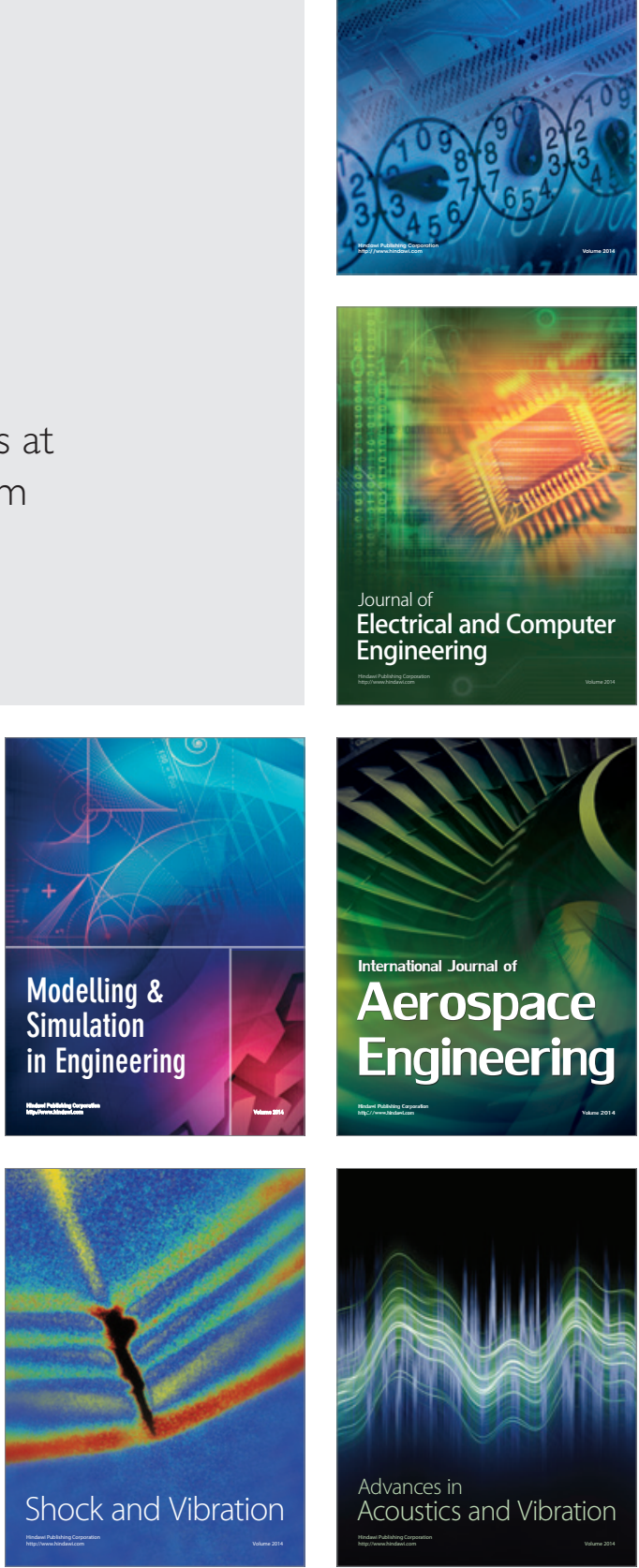